Florida International University FIU Digital Commons

$11-8-2011$

\title{
Does Response Topography Affect Response Rates and Behavioral Persistence in Fixed-ratio Schedules?
}

Paloma Pedraza

Florida International University, ppedraza@fiu.edu

DOI: $10.25148 /$ etd.FI11120912

Follow this and additional works at: https://digitalcommons.fiu.edu/etd

\section{Recommended Citation}

Pedraza, Paloma, "Does Response Topography Affect Response Rates and Behavioral Persistence in Fixed-ratio Schedules?" (2011). FIU Electronic Theses and Dissertations. 536.

https://digitalcommons.fiu.edu/etd/536 


\title{
FLORIDA INTERNATIONAL UNIVERSITY
}

Miami, FL

DOES RESPONSE TOPOGRAPHY AFFECT RESPONSE RATES AND BEHAVIORAL PERSISTENCE IN FIXED-RATIO SCHEDULES?

\author{
A thesis submitted in partial fulfillment of the \\ requirements for the degree of \\ MASTER OF SCIENCE \\ in \\ PSYCHOLOGY \\ by \\ Paloma Pedraza
}

2011 
To: Dean Kenneth Furman

College of Arts and Sciences

This thesis, written by Paloma Pedraza, and entitled Does Response Topography Affect Response Rates and Behavioral Persistence in Fixed-ratio Schedules, having been approved in respect to style and intellectual content, is referred to you for judgment.

We have read this thesis and recommend that it be approved.

$\begin{array}{r}\text { Mary Levitt } \\ \hline \text { Martha Pelaez } \\ \hline \text { Jacob Gewirtz, Major Professor }\end{array}$

Date of Defense: November 8, 2011

The thesis of Paloma Pedraza is approved.

Dean Kenneth Furton
College of Arts and Sciences

Florida International University, 2011 


\section{DEDICATION}

I dedicate this thesis to my wonderful husband, Dan. It was with his support, love and patience that I was able to focus on my studies and complete this thesis. 


\section{ACKNOWLEDGMENTS}

I would like to thank all of the members of my committee for all of their support and assistance in completing this thesis. In particular, I would like to thank my major professor, Dr. Jacob Gewirtz, for allowing us to conduct research that challenges the status quo. In addition, I would like to thank Dr. Maricel Cigales for her support and guidance through this process. It was very reassuring to have the insight of someone who was in my shoes not too long ago. Finally, I would like to thank my colleagues, Desiree Espinal and Andre Maharaj for their feedback, editing, and statistical knowledge. 


\begin{abstract}
OF THE THESIS
DOES RESPONSE TOPOGRAPHY AFFECT RESPONSE RATES AND

BEHAVIORAL PERSISTENCE IN FIXED-RATIO SCHEDULES?
\end{abstract}

\author{
by \\ Paloma Pedraza \\ Florida International University, 2011 \\ Miami, Florida \\ Professor Jacob Gewirtz, Major Professor
}

The purpose of this study was to compare response rates and resistance to extinction in single-task and multiple-task phases. Research was conducted with thirty undergraduate college students in a controlled experimental setting. Each Participant was exposed to 4 treatment phases: single-task, fixed-ratio of one (ST-FR1), multiple-task fixed-ratio of one (MT-FR1), single-task fixed-ratio of 5 (ST-FR5) and multiple-task fixed-ratio of 5 (MT-FR5) all beginning with a baseline phase and reverting back to baseline after the first two conditions were presented. Half of the Participants received the single-task phase first, and the other half received the multiple-task phase first, in order to observe the behavior in transition. A trials-to-criterion measure was used to determine how long it took each Participant's behavior to adapt to the new contingency in the next phase, which was presented without any signal.

The data reveal that regardless of the order of phase presentation it took Participants more than twice as long to reach the criterion in the single-task phases, than in the multipletask phases. 


\section{TABLE OF CONTENTS}

CHAPTER

PAGE

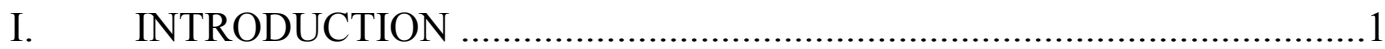

II. LITERATURE REVIEW ........................................

Schedules of Reinforcement Research.................................

Responding under Fixed-ratio Schedules............................

Behavioral Persistence.............................................. 3

Response Variability as the Dependent Variable ...........................5

Response Variability as the Independent Variable........................5

III. METHODOLOGY.................................................

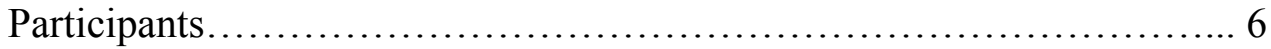

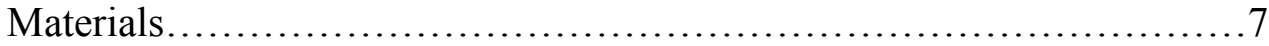

Data Collection/Validity Measures............................... 7

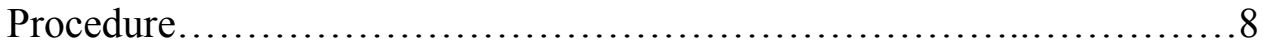

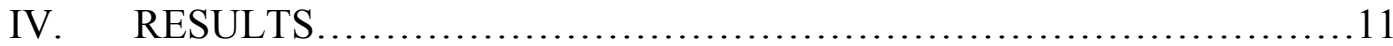

Rates of Responding .............................................. 11

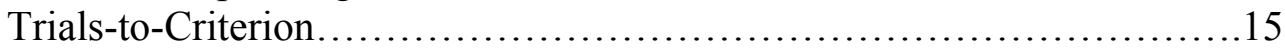

Sequence Effects in Trials-to-Criterion................................17

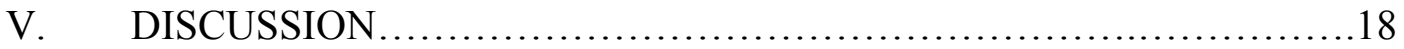

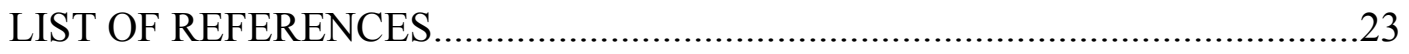

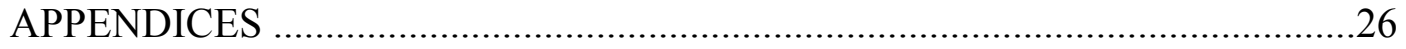




\section{$\underline{\text { INTRODUCTION }}$}

In behavior analysis, the basic literature has touched on the variety of aspects of the environment that affect behavior. Variables such as schedules of reinforcement, antecedent stimulus conditions, and the availability of choice have all been shown to affect the act of response. Central to the theory of behavior, these basic studies have typically used only one topographic response class (Ferster \& Skinner, 1957, among others). Species-specific responses have been selected such as lever presses or key pecks, out of convenience, to study behavior in controlled environments and have been used to make inferences about human responding in uncontrolled environments (Pierce \& Cheney, 2009). However, singular, repetitive behavior is not representative of typical human behavior, as humans show a wide range of behavioral variability. It is this variability that allows adaptive functioning in novel environments and continued responding in challenging conditions (Catania, 2007).

The purpose of this study was to allow a variety of responses to occur and be reinforced within a brief session in a controlled environment, and to present changes in the reinforcement contingencies without explicit warning, providing a challenging condition for the previously reinforced response. This study aimed to contrast response rates in single-task versus multiple-task phases under two different schedules of reinforcement: FR1 and FR5. It also served to compare the number of trials a Participant needed to reach an arbitrary criterion in each type of task situation and to observe possible differences in this measure as a function of sequence. 


\section{LITERATURE REVIEW}

\section{Schedules of Reinforcement Research}

Studies on schedules of reinforcement have manipulated all aspects of the threeterm contingency commonly known in behavior analysis as the A-B-Cs. Antecedent stimuli have been manipulated in terms of presenting or not presenting a signal (Richards, 1981), the salience of the stimulus (Barry, 2004), and the modality of the stimulus used (Schlinger \& Blakely, 1994). Consequential stimuli have also been manipulated in various ways including providing choice among reinforcing alternatives (Dyer, Dunlap \& Winterling, 1990; Fisher, Thompson, Piazza, Crosland \& Gotjen, 1997; Tiger, Hanley \& Hernandez, 2006), identifying differences in responding using high preference reinforcers versus low preference reinforcers (Fisher et al., 1992; Roscoe et al., 1999) and using token economies as a way of providing access to a variety of reinforcers (Ayllon \& Azrin 1964, 1968; Birnbrauer, Wolf, Kidder \& Tague, 1965). However, the response itself has not been given much attention. The most common aspects that have been manipulated are the size of the ratio or interval (how many times the response must occur before reinforcement is available or how much time must pass before a response may be reinforced), and how different schedules interact to create complex schedules of reinforcement (Orlando \& Bijou, 1960). While there has been some attention paid to variability in responding as a dependent variable (Grunow \& Neuringer, 2002), variability in the topography of the behavior itself has not been looked at as an independent variable in the basic research. Responding under Fixed-ratio Schedules

Ratio schedules indicate that reinforcement will be delivered following some 
number of responses. A fixed-ratio schedule indicates that the number of responses required for reinforcement will be the same each time (Malott, 2008). Because of the predictable nature of reinforcement delivery, responding under fixed schedules tends to produce choppy patterns of responding as illustrated by the stair-step patterns produced in the cumulative record of fixed-ratio schedules. The stair-step pattern is often attributed to the pause in responding that tends to occur following reinforcement (post-reinforcement pause) which is positively correlated with the size of the reinforcement schedule (Catania, 2007). In other words, the thinner the schedule of reinforcement, the longer the pause will be, causing the overall rates of responding to drop. Variable ratio schedules, on the other hand, tend to produce smooth and steady patterns of responding, with typically higher overall rates of responding, particularly when the schedule is thinner (Malott, 2008). As was mentioned above, all of the studies conducted in this area rely on the use of single response topographies. What would be of interest to my study would be to determine if providing a variety of response options within a fixed-ratio schedule resulted in the same stair-step pattern demonstrated in the single response paradigm, or if those response options decrease the likelihood of observing the post-reinforcement pause. Because a cumulative recorder was not available for this study, comparing response rates in the single- versus multiple-task phases at the FR5 level will provide some information toward this end.

\section{Behavior Persistence}

When training adaptive behavior, one of the major treatment goals is that the behavior will maintain once formal training has ended. Because reinforcement in the natural environment is unpredictable, responses must be resistant to periods of non- 
reinforcement (extinction). Typically, aspects of the reinforcement schedule are altered in order to increase resistance to extinction such as reinforcing responses variably and on gradually thinner schedules (Kazdin, 2001). However, the idea that variability in the topographical response class might affect behavioral persistence (or resistance to extinction) has not been tested.

In addition, aspects of generalization training are included in order to increase the likelihood of responding in the presence of novel stimuli. However, such training tends to focus on the use of a variety of stimuli within a stimulus class, and not on a variety of functionally equivalent responses, as was prescribed by Baer, Wolf, and Risley (1987). The tendency to focus on environmental stimuli may be a result of the increased response effort on the part of the trainer to train various responses, rather than a single one; as opposed to simply showing different stimuli and prompting the same response. However, noting the bidirectional nature of the organism and its environment; where the organism influences its environment, and the environment influences the organism; it seems just as important to focus on training various responses that could function in a variety of situations, rather than a single response that is expected to function in any situation. As was noted in the same 1987 article, Baer, Wolf, and Risley mention that many of the recommendations regarding generalization have not been empirically validated and thus beg for experimentation. Current studies that look at generalization still seem to focus primarily on aspects of the environment, such as training in natural environments (Koegel, Koegel \& Schreibman, 1991) and using peer trainers (Pierce \& Schreiber, 1995). While this is certainly a move in the right direction in terms of promoting generalization, studies still have not looked specifically at how reinforcing a variety of 
responses affects behavioral persistence. A study such as mine provides a platform to compare responding when there is a single response topography with responding when there are multiple response topographies on equivalent schedules of reinforcement and in situations where the previously reinforced contingencies are put on extinction. Response Variability as the Dependent Variable

There have been many studies looking at the causes of behavioral variability (e.g., Boren, Moerschbaecher \& Whyte, 1978; Eckerman \& Lanson, 1969; Antonitis, 1951). It is well established, for example, that periods of non-reinforcement lead to novel responses (Pierce \& Cheney, 2008; Antonitis, 1951), and thus greater response variability. Response variability is adaptive, and allows the organism to access the reinforcer using a new response when the previously reinforced response is no longer effective. Some studies (Paige \& Neuringer, 1985) have also suggested that variability can be directly reinforced by reinforcing novel responses. Because of the adaptive nature of response variability, it has been important to understand how variability can be increased. Various aspects of reinforcement schedules have been manipulated in multilever operant chambers to attempt to determine when variability is most likely. Boren et al. (1978) for example, looked at differences in response variability in fixed versus interval schedules ranging from FR1 to FR300, and FI 0.06 minutes to FI 4-minutes, respectively. He found that there was greater variability in less-dense interval schedules (FI 0.5 min. - FI 4 min.) than in any other type of schedule. He also found that fixedratio schedules, regardless of how dense the reinforcement schedule was, resulted in little variability. Thus, there is more to variability than density of reinforcement such as efficient response allocation. In the current study, an additional step was added to 
equalize efficiency in response allocation across single- and multiple- task phases. Response Variability as the Independent Variable

One applied study has used variability in responding as an independent variable. Dunlap and Koegel (1980) compared correct responding in a single-task phase to a multiple-task phase with children with autism and showed positive effects in the multiple-task phase including increased percent correct responding, and subjective measures of improvement in the child's mood. Dunalp and Koegel (1980) began to discuss the differences in responding when there is only one task available versus when there are a variety of tasks available. However, its focus was to improve the teaching methods of a clinic and not simply to study the effects of task variety. Dunlap and Koegel's 1980 study did lead to improvements in the way trainings are conducted, such as with pivotal response training (PRT) (Koegel et al., 1991), which emphasizes training loosely and with a variety of target behaviors. However, further information such as differences in rates of responding and resistance to extinction following each type of task phase would provide more information about how response variability specifically affects responding.

\section{METHODS}

\section{Participants}

The first thirty participants who volunteered from the psychology research participant's pool were selected. All of the participants who volunteered were taking an introductory psychology course and were required to participate in studies. About half of the Participants were male $(n=13)$ and half were female $(n=17)$ and all but one were between 18-24 years of age. Participants were compensated in the form of prizes 
selected from a "treasure box" for completing tasks as a form of positive reinforcement in a token economy. The type and number of prizes received varied depending on the number of tasks completed but was fairly similar across participants. The prizes included candy and healthy snacks, pens, pencils, highlighters and other school and office supplies. Participants also received one credit towards their study requirements.

\section{Materials}

A device (see Appendix B) created specifically for this experiment provided five operands for responding on a single surface, spaced about two inches from each other. The operands were all basic switches common in most households including a typical light switch, a sliding light dimmer, a dial light dimmer, a doorbell button and a pulling chord like those typically seen on ceiling fans. The device had a counter that indicated the total number of responses and the number of responses per switch. A digital clock was used to determine the duration of the session and a hand-held mechanical counter was used to count the reinforced responses within the session. Reinforcement was delivered immediately in the form of the sound produced by a table bell, activated by the researcher. Following the experiment the Participants were able to select prizes from several treasure boxes labeled 20-points, 50-points and 100-points in some combination, depending on the number of times the bell was rung. All of the sessions were video recorded using a Flip camera and the videos were immediately uploaded to a password protected computer.

\section{Data collection/validity measures}

Data were collected on rates of responding by looking at the total number of responses emitted via the counting mechanism on the device and dividing that by the time 
spent in the session as recorded by the observer. In order to have momentary rates of responding to observe patterns of responding in single-case graphs, frequency was also collected in 30-second bins by watching videos of each Participant and counting the number of responses emitted every 30 -seconds. Trials-to-criterion data were collected by watching the videos again and determining when reinforcement for a particular condition ended, signaling that the criterion had been met and the next phase was about to begin. The responses counted up to that point were added to determine how many responses were made before the criterion was met. Inter-observer agreement for rates of responding was collected by a research assistant for every third session by dividing the smaller rate measure by the larger rate measure for each Participant to obtain a percentage of agreement score (Bijou, Peterson, Harris, Allen, \& Johnston, 1969). The average interobserver agreement for rates of responding was $93.98 \%$ and ranged from $79.55 \%$ to $99 \%$ across participants.

Data were analyzed using visual inspection by graphing the data on each measure for each participant, and graphing mean data across all participants. Visual inspection (or graphic data analysis) is commonly used in single-case research because in most cases "when the differences are large and the relationships are clearly apparent there is little need for statistical tests" (Bijou et al., 1969). One of the tenets of behavior analytic research is that "the more an analytic procedure changes the investigator's picture of the subject's behavior as it actually happened, the greater the risks that the analytical procedure may exert more control over interpretations than do the data" (Johnston \& Pennypacker, 1993). However, because the sample size was much larger than in a typical single-case experiment, correlated-groups $t$ tests were also used to compare the means of 
the rates of responding, as well as trials-to-criterion across conditions. Correlated groups $t$-tests were used because the data fit all of the assumptions of such a test: the data were normally distributed, the dependent variable was quantitative and on an interval scale, there were two levels of the independent variable (single- and multiple-task phases), and the independent variable was presented within subjects (Jaccard \& Becker, 2002).

\section{Procedure}

Prior to the experiment the participant was shown the treasure boxes and the points system was explained. They were also told that every time the bell made a sound they had accumulated one point towards objects from the boxes and would be able to redeem them at the end of the session. The instructions served as the training condition for the token economy in this study. The sound was expected to function as the conditioned reinforcer via rule-governance (Hayes, 1989), where the contingency is verbally mediated.

Once the points system was explained, participants were asked to sit down at a table with the device. Each operandum was manipulated by the researcher first, and then Participants were asked to manipulate each of the operandum following the demonstration to ensure that they would be manipulated correctly and to threshold (some of the switches required a certain degree of magnitude to activate the electronic counting mechanism). They were also told to touch a "home plate" that was placed directly in front of them, between the Participant and the device, after each manipulation. The purpose of the "home plate" was to account for some of the differences in time allocated to moving between operandi as opposed to manipulating the same operandum repeatedly.

They were reminded that their hands would be video recorded and told to begin 
manipulating the operandi in any manner they chose, once the researcher was ready to begin. They were not given instructions on where to begin or at what pace they should proceed. Participants were not told the contingencies of when the bell would sound to ensure that the response was actually being reinforced by the sound of the bell and not being controlled by verbal instructions.

A reversal design (Baer et al., 1968) was used, beginning with baseline and returning to baseline after each experimental phase. The sequence of phase presentation was counterbalanced for every other Participant such that half of the Participants began with a single-task phase and the other half began with a multiple-task phase, in order to observe carryover effects from one condition to the next. Each condition began with a baseline phase to determine the rate of responding prior to reinforcement. The independent variable was presented on a continuous schedule of reinforcement (FR1) in the first presentation of conditions and then following a return to baseline, was presented on a fixed-ratio of five responses (FR5) for the second presentation of conditions. Fixedratio schedules were selected over variable ratio, or interval schedules because they tend to produce the least variability (Boren et al., 1978), allowing the experimenter to have as much control over the variability of the responses as possible.

Phase presentation is illustrated in Table 1.

\begin{tabular}{|c|c|c|c|c|c|c|}
\hline \multicolumn{7}{|c|}{ Phase Presentation Sequence Across Participants } \\
\hline \multirow{3}{*}{ Odd \# pp } & A & B & C & A & D & E \\
\cline { 2 - 7 } & \multirow{3}{*}{ BL } & $\begin{array}{c}\text { Single- } \\
\text { Task }\end{array}$ & $\begin{array}{c}\text { Multiple- } \\
\text { Task }\end{array}$ & BL & $\begin{array}{c}\text { Single- } \\
\text { Task }\end{array}$ & $\begin{array}{c}\text { Multiple- } \\
\text { Task } \\
\end{array}$ \\
& FR1 & FR1 & & FR5 & FR5 \\
\hline \multirow{3}{*}{ Even \# pp } & & C & B & A & E & D \\
\cline { 2 - 7 } & BL & Multiple- & Single- & & Multiple- & Single- \\
& & Task & Task & BL & Task & Task \\
& & FR1 & FR1 & & FR5 & FR5 \\
\hline
\end{tabular}


Table 1. Phase presentation sequence

Each phase went as follows:

Phase A: Baseline (control): As soon as the Participant began manipulating operandi each response was counted. Once 50 responses were counted, the independent variable was introduced.

Phase B: Single-task FR1. The bell was rung each time the same response as the previous response was selected. If the Participant moved onto a different operandum, that response was not reinforced. The criterion for termination in this phase was 20 consecutive manipulations of the same operandum. Once the criterion was met, the next condition was presented.

Phase C: Multiple-task FR1. The bell was rung each time a different response from the previous response was selected. If the Participant selected the same operandum, that response was not reinforced. The criterion for termination in this phase was 20 consecutive manipulations of different operandi. Once the criterion was met, the next condition was presented.

Phase D: Single-task FR5. The bell was rung after the fifth time the same response was selected consecutively. If the Participant moved onto a different operandum before five consecutive manipulations, the count was reset. The criterion for termination in this phase was 10 consecutive runs of five manipulations of the same operandum. Once the criterion was met, the next condition was presented, or the study was ended, depending on the sequence of phase presentation.

Phase E: Multiple-task FR5. The bell was rung after the fifth time a different response was selected. If the Participant selected the same operandum twice, the count 
was reset. The criterion for termination in this phase was 10 consecutive runs of five manipulations of different operandi. Once the criterion was met, the next condition was presented, or the study was ended, depending on the sequence of phase presentation.

\section{$\underline{\text { RESULTS }}$}

Rates of Responding:

Mean rates of responding are outlined in Table 1. The lowest rates of responding occurred in the initial baseline, before any responses were reinforced. The second baseline is not quite as low as the first baseline, indicating that on average, there was not a full return to baseline, which is important in a within-subjects design. For this reason, it may be valuable to compare all conditions to the first baseline, including conditions that were presented following the second baseline. The purpose of including a second baseline was to un-do the conditioning that occurred in the first two experimental phases but this may not have occurred completely, perhaps as a result to the brevity of the second baseline as compared to the experimental phases that it followed.

\begin{tabular}{|c|c|c|}
\hline Condition & $\mu$ rate per 30 sec & $S D$ \\
\hline BL- 1 & 17.41 & 5.89 \\
\hline ST- FR1 & 19.98 & 5.98 \\
\hline MT- FR1 & 29.05 & 5.63 \\
\hline BL- 2 & 20.31 & 6.41 \\
\hline ST- FR5 & 21.12 & 7.08 \\
\hline MT- FR5 & 20.96 & 6.78 \\
\hline
\end{tabular}

Table 2. Average Rate of Response per 30-second interval 


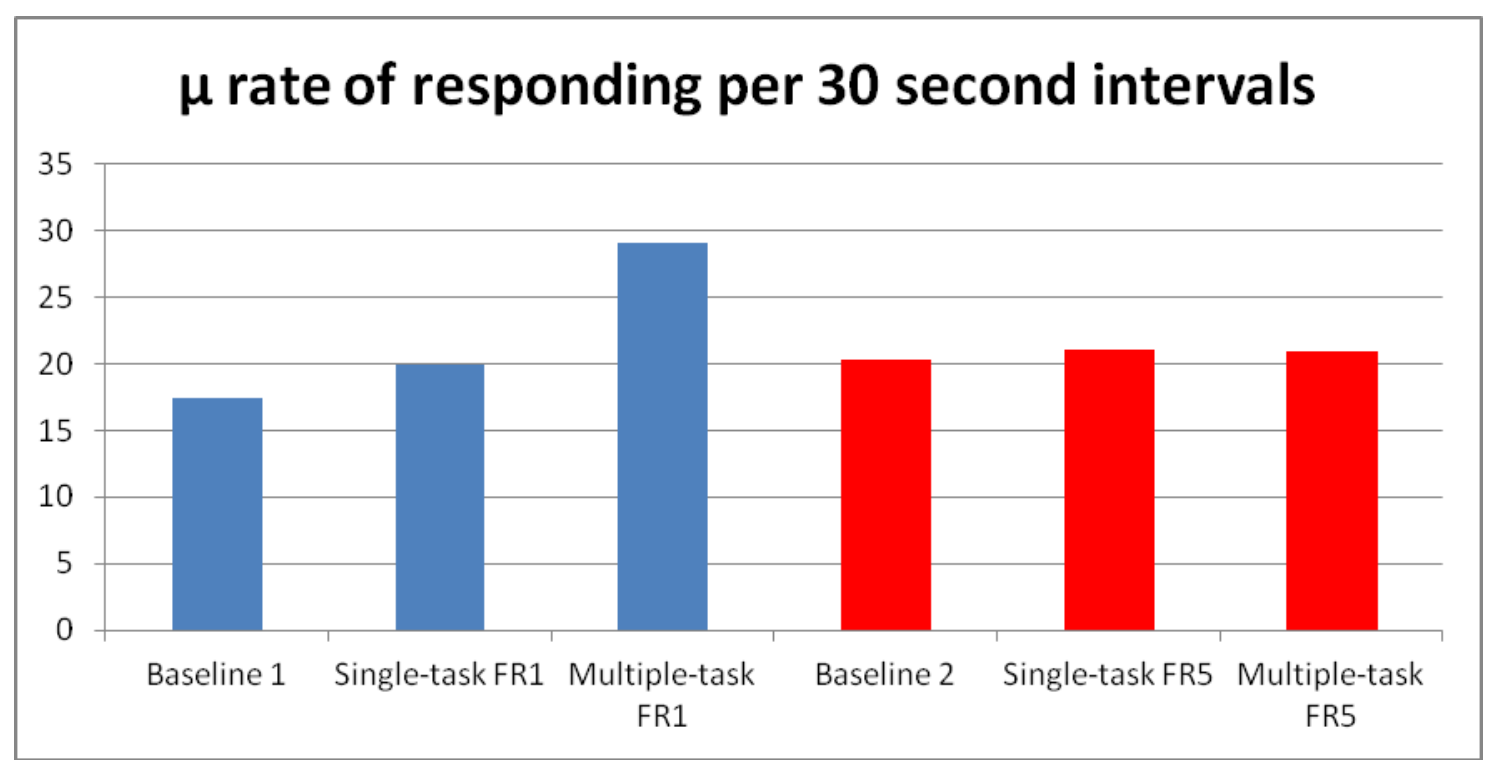

Figure 1. Average rate of responding per 30-second interval.

The fastest rates of responding occurred in the multiple-task FR1 phase. When looking at Figure 1, it appears that when comparing single- and multiple-task phases within a particular level of reinforcement (FR1 vs. FR5) the largest difference occurred at the FR1 level. Those differences were not evident when comparing single- versus multiple-task phases at the FR5 level. For a more fine grained analysis, inferential statistics were also used to compare the means. The data were tested for normality by standardizing the samples and comparing the sample for each measure to a standard normal distribution using the Kolmogorov-Smirnov test (Lilliefors, 1967). After confirming normality, the data were analyzed using a correlated-groups $t$ test (Jaccard et al., 2002). The results are in Table 3, below. 


\begin{tabular}{|c|c|c|c|c|}
\hline Comparison & $t$ & $p$ & $D F$ & $C I$ \\
\hline BL-1 vs. ST-FR1 & -3.625 & $<.001$ & 29 & $-4.27014--1.18986$ \\
\hline BL-1 vs. MT-FR1 & -2.369 & $<.05$ & 24 & $-4.42364--.30436$ \\
\hline BL-1 vs. BL-2 & -2.094 & $<.05$ & 24 & $-4.18189--.03011$ \\
\hline BL-1 vs. ST-FR5 & -2.489 & $<.05$ & 24 & $-5.29010--.49390$ \\
\hline BL-1 vs. MT-FR5 & -2.337 & $<.05$ & 23 & $-4.86204--.29630$ \\
\hline BL-2 vs. ST-FR5 & -1.497 & .148 & 24 & $-1.86998-.29798$ \\
\hline BL-2 vs. MT-FR5 & -.920 & .367 & 23 & $-1.52929-.58763$ \\
\hline ST-FR1 vs. MT-FR1 & .868 & .394 & 24 & $-.63918-1.56718$ \\
\hline ST-FR5 vs. MT-FR5 & .932 & .361 & 23 & $-.46009-1.21426$ \\
\hline
\end{tabular}

Table 3. Correlated groups $t$ test $\alpha=.05$ for rates of responding

All of the conditions were shown to be significantly different when they were compared to the initial baseline phase (BL-1), demonstrating that the reinforcer used during the study was likely effective in increasing response rates across conditions. There were also significant differences when comparing the first and second baselines, confirming the lack of a complete return to baseline. The lack of significance between the second baseline and the conditions that followed it (ST- and MT-FR5) may be attributed to the lack of a complete return to baseline. Interestingly, there was also a lack of significance in the differences between experimental conditions of the same level (STFR1 vs. MT-FR1 and ST-FR5 vs. MT-FR5). At the FR5 level, this result coincides with what one may interpret from looking at Figure 1. However, as was mentioned before, one of the largest differences visually, was between the single- and multiple-task phases at the FR1 level. The lack of a significant difference here could be attributed to the fact 
that there was a difference in the sample size between the single- and multiple-task conditions. Participant attrition occurred in five cases when the participant began in the single-task phase and emitted 100 responses after baseline without reinforcement, thus never reaching the criterion. At this time the study was stopped and the only data that were collected were rates of responding for baseline and single-task FR1.

From a single-case methodological perspective, it is interesting to note that the variability in range is primarily the result of individual differences in rates of responding. For example, the slowest responding in both of the FR5 conditions, as well as in both baselines came from a single participant (participant 14), while the fastest responding in both baselines, as well as the single-task FR1 and the multiple-task FR5 came from a single participant (Participant 2).

Trials-to-Criterion:

\begin{tabular}{|c|c|c|}
\hline Condition & $\begin{array}{c}\mu \text { trials-to- } \\
\text { criterion }\end{array}$ & $S D$ \\
\hline ST- FR1 & 188.12 & 220.331 \\
\hline MT- FR1 & 71.12 & 55.95 \\
\hline ST- FR5 & 266.13 & 146.116 \\
\hline MT- FR5 & 140.74 & 92.90 \\
\hline
\end{tabular}

Table 4. Average number of trials-to-criterion 


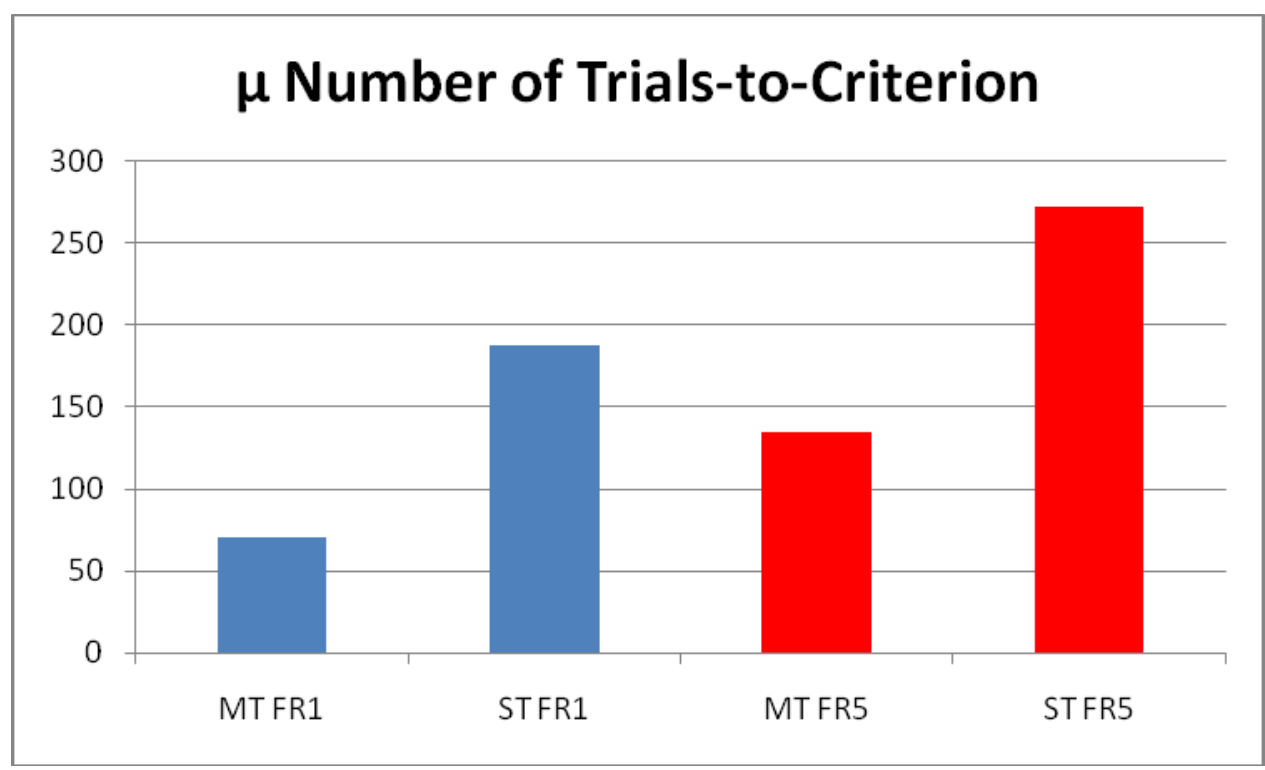

Figure 2. Average number of trials-to-criterion

Mean trials-to-criterion are summarized in Table 3. The number of trials-tocriterion varied greatly across, and within conditions. In general, participants required fewer trials to reach the criterion in the multiple-task phases than the single-task phases when comparing within the same level of reinforcement. It appears that it is easier to come into contact with the reinforcing contingencies when there are multiple responses that are reinforced as opposed to a single one. When looking at the graphed data the differences seem large when comparing within a level of reinforcement. Figure 2 shows the mean trials-to-criterion across conditions.

For the sake of consistency, however, the means were compared using correlatedgroups $t$ tests as well. After running the Kolmogorov-Smirnov test, only half of the data sets were found to be normally distributed. Interestingly, it was both of the conditions at the FR1 level that were not normally distributed. Although the ranges across all conditions were relatively high, the single-task FR1 phase had a particularly large $S D$ and could have attributed to the non- normal distribution. Proportionally, the $S D$ for the 
multiple-task phase in FR1 is also quite large, though not as large as in the single-task condition. Since comparisons were not made across levels, only the data at the FR1 level was recoded using a natural log transformation and the FR5 data was left as-is. The results are in Table 4.

\begin{tabular}{|c|l|l|l|c|}
\hline Comparison & \multicolumn{1}{|c|}{$t$} & \multicolumn{1}{c|}{$p$} & & DF \\
\hline STFR1 vs.MTFR1 & 3.793 & $<.001$ & 24 & $.348-1.18$ \\
\hline STFR5 vs. MTFR5 & 3.522 & $<.01$ & 23 & $51.73-199.020$ \\
\hline
\end{tabular}

Table 5. Correlated groups $t$ test $\alpha=.05$ for trials-to-criterion

As expected, the differences across conditions were significantly different at both levels. It should be noted that the comparisons were run with and without the log transformation and significance was found each time, however, since one of the assumptions of a $t$ test is that the data are normally distributed, only the results when the data fit the assumptions were shown.

Sequence Effects in Trials-to-Criterion:

\begin{tabular}{|l|l|l|l|l|}
\hline \multicolumn{1}{|c|}{ Sequence } & ST FR1 & MT FR1 & \multicolumn{1}{|c|}{ ST FR5 } & MT FR5 \\
\hline Single-task presented first & 187.1 & 68.7 & 279 & 148 \\
\hline Multiple-task presented first & 188.8 & 72.67 & 258.4 & 136.40 \\
\hline
\end{tabular}

Table 6 . Trials-to-criterion by order of phase presentation 


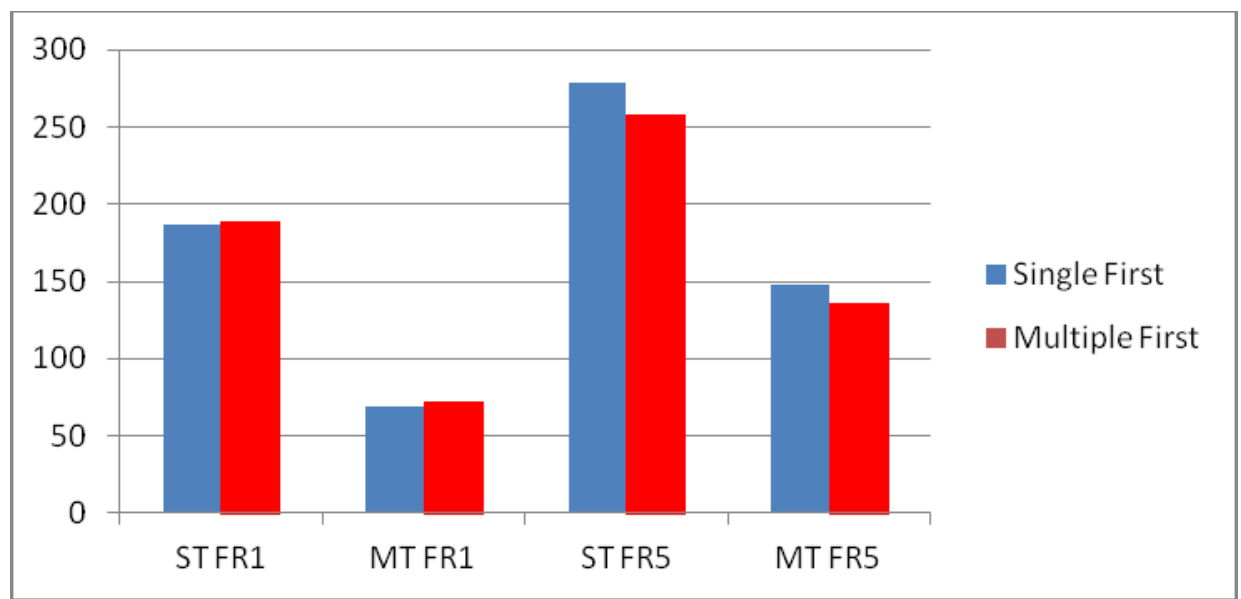

Figure 3. Trials-to-criterion in terms of sequence

Because the sample size is cut in half when looking at sequence effects, the value of analyzing using inferential statistics drops off and may not be useful. Visually, when comparing conditions in terms of sequence effects, it does not seem that the differences are large, nor significant. However, it is interesting to note that when the multiple-task phase followed baseline it took slightly longer to learn the contingency than when it followed the single-task phase at the FR1 level. Perhaps it was easier to distinguish the change in contingency after having had a single task reinforced continuously, and suddenly no longer being reinforced, rather than having no tasks reinforced at all. It also seems that this minor sequence effect at the FR1 level switches at the FR5 level - it took slightly longer to get the multiple-task contingency following the single-task contingency, rather than following the second baseline. It is unclear why this switch occurred, but one possibility is that after having received reinforcement for five of the same consecutive responses, the contingency was set at multiples of the same response. However, in all cases it took longer to reach the criterion in the single-task phases than it did in the multiple-task phases, therefore sequence did not seem to be an important factor in this study. 


\section{$\underline{\text { DISCUSSION }}$}

\section{Patterns of responding}

Although the data for rates of responding were presented in single-case, time-series graphs, it was still difficult to determine if there were differences in patterns of responding between the single- and multiple-task phases. Because it was difficult to graph reinforcer delivery contingent on the response, it was impossible to tell if there was any indication of post-reinforcement pausing. The difference between single- and multiple-task phases may have been evident in the FR5 conditions, since the pause generally increases as rates of reinforcement decrease (Catania, 2007; Felton \& Lyon, 1966). However, without a cumulative recorder it is difficult to say if having multiple response options ameliorates post reinforcement pausing when compared to a single response option. Since greater pausing would cause overall rates of responding to decrease, we could look at the rates across conditions and draw an inference from that data. However, the only time that the rates seemed different was in the FR1 condition, where post-reinforcement pausing is at its lowest. Therefore, it seems that at these relatively high ratios of reinforcement, there were no obvious differences in rates of responding that were a result of decreased pausing. Using a cumulative recorder and lower reinforcement ratios would allow the investigator to draw some better conclusions about this assumption.

\section{Behavioral Persistence}

One area where the study only showed a slight difference was in how single- versus multiple-task phases fared under a new contingency. One thought was that when moving from a multiple-task phase to a single-task phase there would be greater resistance to 
extinction because there were a variety of responses that were reinforced. In fact, it did take 1.6 extra responses (on average) to reach the criterion in the single-task phase when it followed the multiple-task phase, as opposed to baseline, in the FR1 conditions. Along these lines, one might expect that when moving from a single-task phase to a multipletask phase, that change would occur more quickly, following the assumption that a single response has a lower resistance to extinction than do multiple responses. The faster aquisition was also demonstrated when it took approximately four extra responses (on average) to reach the criterion in the multiple-task phase when it followed baseline as opposed to the single-task phase.

However, these differences did not seem very large and may have been more evident if the criteria were more stringent (i.e., took longer to reach). One possibility for the similarity in the number of trials-to-criterion may be because the comparison phase always either followed an experimental phase or a baseline phase. Thus, when comparing one experimental condition to another experimental condition or to a baseline, those that follow the experimental condition had the benefit of detecting some contingency, whereas those who come straight from baseline have a less obvious change in contingency. For example, when a single response was reinforced repeatedly and suddenly was no longer reinforced, the change in contingency was more obvious to the participant and he quickly changed his responses; whereas when the participant left the baseline condition he had to accidentally come into contact with the contingency the first time before it could be reinforced. Even with this asymmetrical start, there were the expected (however subtle) differences.

This finding is not the same when looking at the FR5 level of conditions. First, it is 
important to note that it does not seem that the second baseline was long enough to return rates of responding back to original baseline levels. Thus, it is possible that there was some influence from the first two conditions on the last two conditions. This is not necessarily something that invalidates the study or the design, since the FR1 conditions were put in place to establish some level of control from the reinforcer, and the second baseline may have not been necessary. Be that as it may, there was a complete reversal of the results at the FR5 level, where it took an extra 19.6 responses (on average) to reach the criterion in the single-task phase when it followed baseline, as opposed to the multiple-task phase. It also took an extra 12.4 responses (on average) to reach the criterion in the multiple-task phase when it followed the single-task phase, as opposed to baseline. These findings do not validate the assumption that a multiple-task contingency has a higher resistance to extinction than a single-task contingency. However, because of the comparison of experimental phases to baseline phases, and because of the nature of the second baseline, it is difficult to say if this is a constructive finding or not.

In the future, it would be useful to use an alternating treatments design (Catania, 2007), using a single level of reinforcement and going back and forth between single- and multiple- task phases. Also, using lower ratios of reinforcement would allow the investigator to see the behavior in transition more readily. It seemed to take longer for the criteria to be met in the FR5 condition, as opposed to the FR1 condition, where there was often reinforcement available, even if the criterion was not being met. Thus, conditions in the FR5 phases were more challenging and required more trials to detect the new contingency, making a more robust comparison. 


\section{Limitations}

There were five instances in which the participant began responding in a pattern that was inadvertently reinforced, preventing him from reaching the phase criterion. For example, in the single-task phase, a participant would hear the bell after pressing the same manipulandum consecutively, but then move on to another manipulandum, press that one twice, hear the bell again, and continue in that pattern. Thus his behavior of pressing the manipulandum twice and then pressing another one twice was reinforced, but it prevented him from reaching the criterion and moving on to the next phase. When the participant was clearly engaging in a repeated pattern and 100 reinforcers had been delivered, the experiment was terminated because it would not have been consistent with the experiment protocol to explain what was expected. Interestingly, however, the only time that participants did not meet the criteria to move on to the next phase was when the single-task phase was presented first. The participant attrition caused the sample sizes to be different across some conditions and made using inferential statistics a bit more challenging.

Another limitation was in the availability of laboratory equipment. For example, a computer based program could have made the multiple-task contingency so that the previous four responses could not be repeated, as opposed to only being required to manipulate a different operandum from the previous one. The lack of sophistication of the equipment sometimes made the multiple-task contingency one in which a participant moved back and forth between two operandi, which was correct under my paradigm, but not a true reflection of "multiple" tasks. It could have also made reinforcement delivery automatic, and more precise. For example, because the reinforcer delivery was regulated 
by the experimenter, and because response rates were very high (about one per second at times), the reinforcer was sometimes delivered after the participant began engaging in the next response. Piloting prior to the study allowed the experimenter to improve at this before the study began; however, it was impossible to be perfect. 


\section{REFERENCES}

Antonitis, J. J. (1951). Response variability in the white rat during conditioning, extinction, and reconditioning. Journal of Experimental Psychology, 42(4), 273281.

Ayllon T. \& Azrin N. (1964). The measurement and reinforcement of behavior of psychotics. Journal of the Experimental Analysis of Behavior, 8(6), 357-383

Ayllon T. \& Azrin N. (1968). The token economy: A motivational system for therapy and rehabilitation. East Norwalk, CT, US: Appleton-Century-Crofts.

Baer, D.M., Wolf, M., \& Risley, T.R. (1968). Some current dimensions of applied behavior analysis. Journal of Applied Behavior Analysis, 1(1), 91-97

Baer, D.M., Wolf, M., \& Risley, T.R. (1987). Some still current dimensions of applied behavior analysis. Journal of Applied Behavior Analysis, 20(4), 313-327

Barlow, D.H., Nock, M.K., \& Hersen, M. (2009). Single Case Experimental Designs: Strategies for Studying Behavior Change, $3^{\text {rd }}$ ed. Boston, MA: Pearson Education.

Barry, R. (2004) Stimulus Significance Effects in Habituation of the Phasic and Tonic Orienting Reflex. Integrative Physiological \& Behavioral Science 39(3), 166-179

Bijou, S.W., Peterson, R.F., Harris, F.R., Allen, K.E., \& Johnston, M.S., (1974). Methodology for experimental studies of young children in natural settings. In Edwin J. Thomas, Behavior Modification Procedure: A Source Book. Chicago: Aldine Pub Co.

Blakely E. \& Schlinger H. (1988). Determinants of pausing under variable-ratio schedules: Reinforcement magnitude, ratio size, and schedule configuration. Journal of the Experimental Analysis of Behavior, 50(1), 65-73

Cantor G.N., \& Cantor J.H. (1964). Effects of conditioned stimulus familiarization on instrumental learning in children. Journal of Experimental Child Psychology, 1, 71-78. Catania, C.A., (2007). Learning: Interim $4^{\text {th }}$ Edition. New York: Sloan Publishing Cohen S.L., Riley D.S., \& Weigle P.A. (1993). Tests of Behavior Momentum in Simple and Multiple Schedules with rats and pigeons. Journal of the Experimental Analysis of Behavior, 60(2), 255-291.

Dunlap G. \& Koegel R. (1980). Motivating autistic children through stimulus variation. Journal of Applied Behavior Analysis, 13(4), 619-627. 
Dyer K., Dunlap G. \& Winterling V. (1990). Effects of choice making on the serious problem behaviors of students with severe handicaps. Journal of Applied Behavior Analysis, 23(4), 515-524

Eckerman, D. A. and Lanson, R. N. (1969). Variability of response location for pigeons responding under continuous reinforcement, intermittent reinforcement, and extinction. Journal of the Experimental Analysis of Behavior, 12(1), 73-80.

Felton, M., \& Lyon, D.O. (1966). The Post-Reinforcement Pause. Journal of the Experimental Analysis of Reinforcement, 9(2), 131-135

Ferster C.B., \& Skinner B.F. (1957). Schedules of Reinforcement. New York: AppletonCentury-Croft

Fisher W., Piazza C. C., Bowman L.G., Hagopian L.P. (1992). A comparison of two approaches for identifying reinforcers for persons with severe profound disabilities. Journal of Applied Behavior Analysis, 25(2), 491-498

Fisher W., Thompson R.H., Piazza C.C., Crosland K. \& Gotjen D. (1997). On the relative reinforcing effects of choice and differential consequences. Journal of Applied Behavior Analysis, 30(3), 423-438

Hanley G.P., Iwata B.A., \& McCord B.E. (2003). Functional analysis of problem behavior: a review. Journal of Applied Behavior Analysis, 36(1), 147-185.

Hayes, S.C. (1989). Rule-governed behavior: Cognition, contingencies, and instructional control. New York, NY: Plenum Press.

Hutt, C., (1975). Degrees of novelty and their effects on children's attention and preference. British Journal of Psychology, 66(4), 487-492

Jaccard, J., \& Becker, M.A., (2002). Statistics for the Behavioral Sciences $4^{\text {th }}$ ed.. Belmont, CA: Wasdworth/Thomson Learning.

Koegel, R. L., Koegel, L. K., \& Schreibman, L. (1991). Assessing and training parents in teaching pivotal behaviors. In R. J. Prinz (Ed.), Advances in behavioral assessment of children and families (pp. 65-82). London: Jessica Kingsley Publishers.

Lattal, K.A., (2004). Steps and pips in the history of the cumulative recorder. Journal of the Experimental Analysis of Behavior, 82(3), 329-355.

Lilliefors, H.W., (1967). On the Kolmogorov-Smirnov test for normality with mean and variance unknown. Journal of the American Statistical Association, 62(318), 399-402. 
Murphy E.S., McSweeny F.S., Smith R.G., McComas J.J. (2003). Dynamic changes in reinforcer effectiveness: theoretical, methodological, and practical implications for applied research. Journal of Applied Behavior Analysis, 36(4), 421-438.

Orlando R. \& Bijou S.W. (1960). Single and multiple schedules of reinforcement in developmentally retarded children. Journal of the Experimental Analysis of Behavior, 3(4), 339-348

Mechner, F. (1958). Probability relations within response sequences under ratio reinforcement. Journal of the Experimental Analysis of Behavior, 1(2), 109-121.

Page, S., \& Neuringer, A. (1985). Variability Is an Operant. Journal of Experimental Psychology: Animal Processes, 11, 429-452.

Pierce, K.\& Schreibman L.(1995) Increasing complex social behaviors in children with autism: Effects of peer-implemented pivotal response training. Journal of Applied Behavior Analysis, 3(3), 285-296

Richards, R.W. (1981). A comparison of signaled and unsignaled delay of reinforcement. Journal of the Experimental Analysis of Behavior, 35(2), 145-152.

Ringdahl J.E., Vollmer T.R., Marcus B.A., \& Roane H.S. (1997). An analogue evaluation of environmental enrichment: The role of stimulus preferece. Journal of Applied Behavior Analysis, 30(2), 203-216.

Roscoe E. M., Iwata B.A., \& Kahng, S. (1999). Relative versus absolute reinforcement effects: Implications for preference assessments. Journal of Applied Behavior Analysis, 32(4), 479-493

Schlinger, H. \& Blakely, E. (1994). The effects of delayed reinforcement and a responseproduced auditory stimulus on the acquisition of operant behavior in rats. The Psychological Record, 44, 391.

Schoenfeld, W. N. (1968). On the difference in resistance to extinction following regular and periodic reinforcement. Journal of the Experimental Analysis of Behavior, 11(3), 259-261.

Sidman, M., \& Stebbins, W.C. (1954). Satiation effects under fixed-ratio schedules of reinforcement. Journal of Comparative and Physiological Psychology, 47, 114-116

Thompson R.F., \& Spencer W.A. (1966). Habituation: A model phenomenon for the study of neuronal substrates of behavior. Psychological Review, 73, 16-43.

Tiger J.H., Hanley G.P, \& Hernandez E. (2006). An evaluation of the value of choice with preschool children. Journal of Applied Behavior Analysis, 39(1), 1-16 


\section{APPENDICES}
A. Letter of Informed Consent
B. Equipment
C. Single-case graphs 
Appendix A: Letter of Informed Consent 


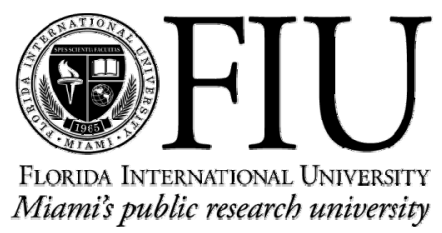

\section{CONSENT TO PARTICIPATE IN A RESEARCH STUDY}

\section{Title: Does Variety in Response Topography Affect Response Rates under Fixed- ratio Schedules}

You are being asked to be in a research study. The investigator of this study is Paloma Pedraza and she is a student at FIU. The study will include about 10-15 people who are student volunteers. Your participation will require 1 hour of your time. We are looking at the relationship between the number of different tasks one has to do and the rates and patterns in which they are done.

You will be asked to activate different types of switches on a small board. Someone in the lab will explain to you how to use the different switches. The switches should be familiar to you and include a regular light switch, a dial light dimmer, a sliding light dimmer, a door bell, and a light cord that you pull. While you are manipulating the switches, your hands will be videotaped. Your face will not be videotaped and the recordings will be saved by your participant number and not your name.

We do not expect any harm to you by being in the study. You may stop at any time if you become fatigued or do not want to continue in the study. You may ask for a break in between parts of the experiment. There is no cost or payment to you as a subject. You will not get any direct benefit from being in the study. However, your help will give us information about how people respond when there is more than one task to do. You will receive a choice of small gifts following the study. The amount or type of gift will depend on your performance in the study, but we expect most people to perform similarly.

The results of your experiment will be identified by a random number not your name. Your name and any other identifying information will not be used in any publication and will not be discussed. We will present the research results individually using your participant number. You may ask questions about the study at any time. If you choose not to participate no one will be upset with you. You may also choose to stop your participation before your finish the study.

If you would like more information about this research after you are done, you can contact Dr. Gewirtz or me at 305-348-3375. If you feel that you were mistreated or would like to talk with someone about your rights as a volunteer in this research study you may 
contact Dr. Patricia Price, the Chairperson of the FIU Institutional Review Board at 305$348-2618$ or $305-348-2494$.

Your signature below indicates that all questions have been answered to your liking. You are aware of your rights and you would like to be in the study.

$\overline{\text { Signature of Participant }} \overline{\text { Printed Name }} \quad$ Date

I have explained the research procedure, subject rights and answered questions asked by the participant. I have offered him/her a copy of this informed consent form.

Signature of Witness

Date 
Appendix B: Equipment 
Fixed versus multiple-task machine:*

1. 5 tasks placed approximately 2 inches apart, encased in a rectangular board, with a hidden on/off switch. The board sits on a table-top and is 2' x 1' $x 1$ '. The tasks are as follows:
A. Light switch (flip, if on then off, if off then on)
B. Light dimmer (turn, if one direction then the other and vice versa)
C. Door bell (push)
D. On/off cord (pull)
E. Slide lock (slide, if one direction then the other and vice versa)

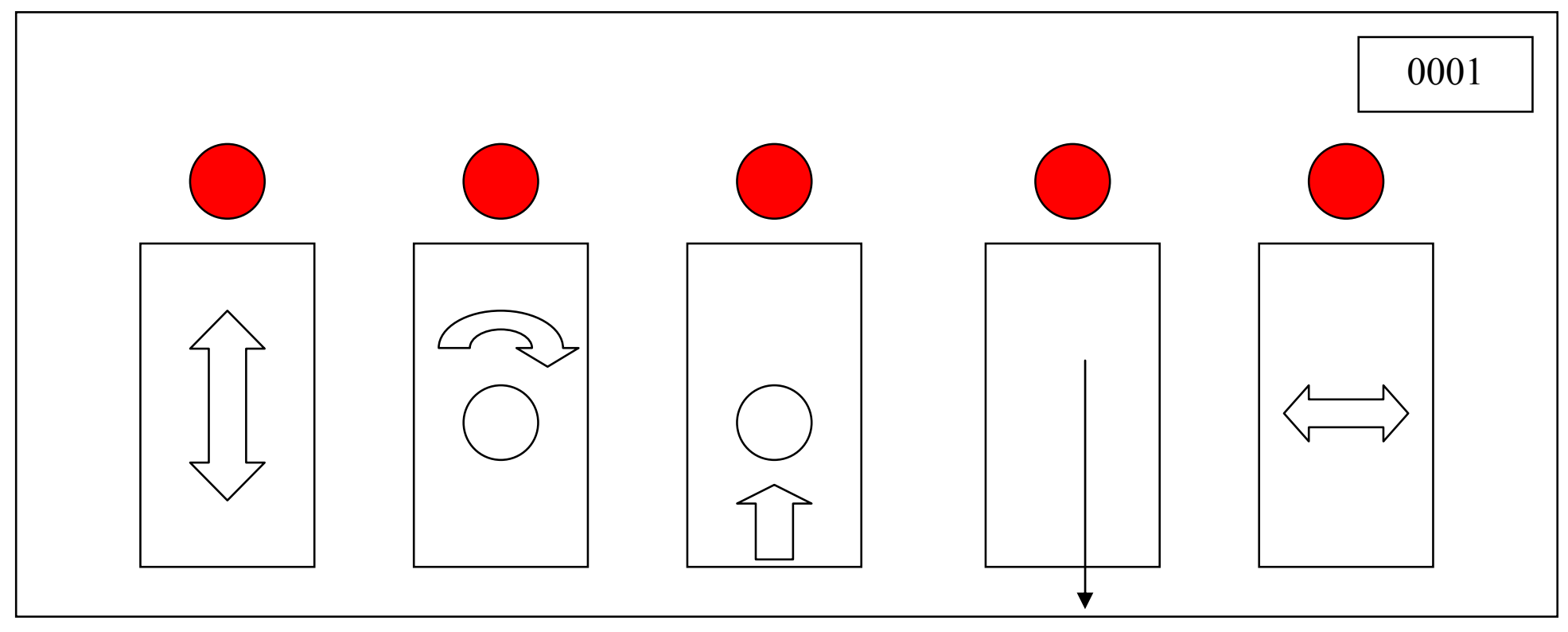

* This device was created for the purposes of this study. It has not been used in any other study. 
Appendix C: Single-case graphs 
Rates of Responding: Frequency of responses per 30-seconds

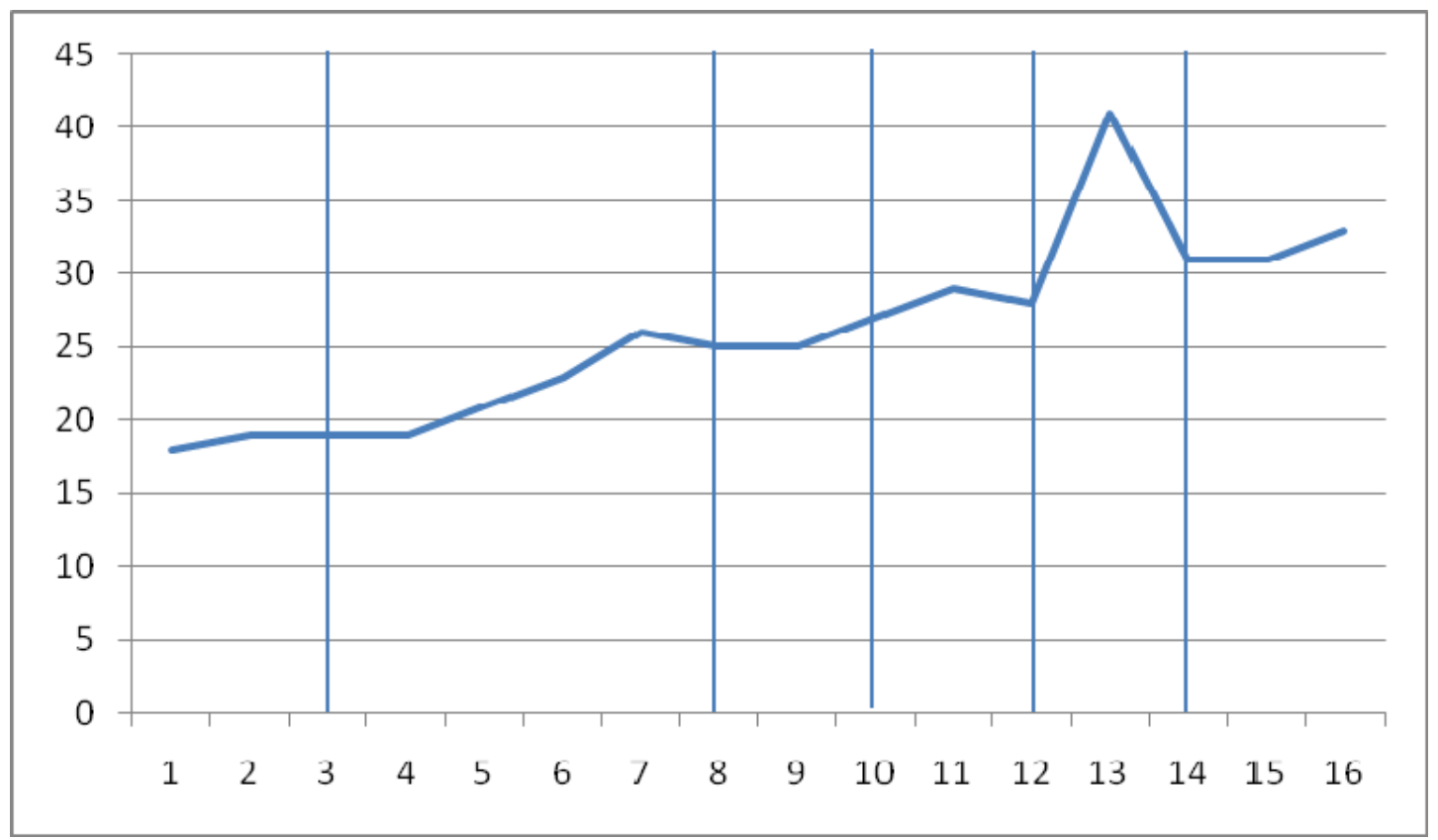

Participant 1

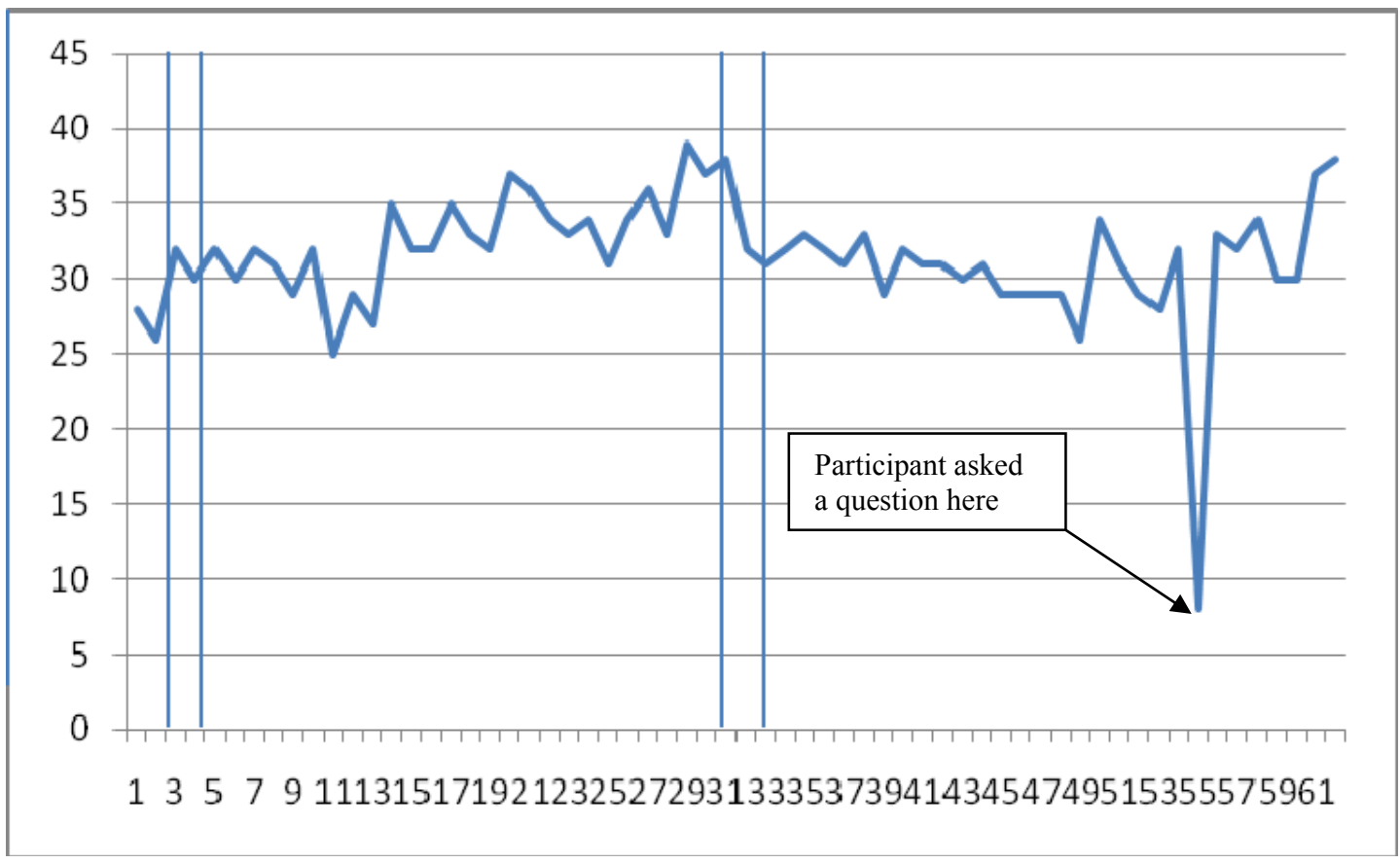


Participant 2

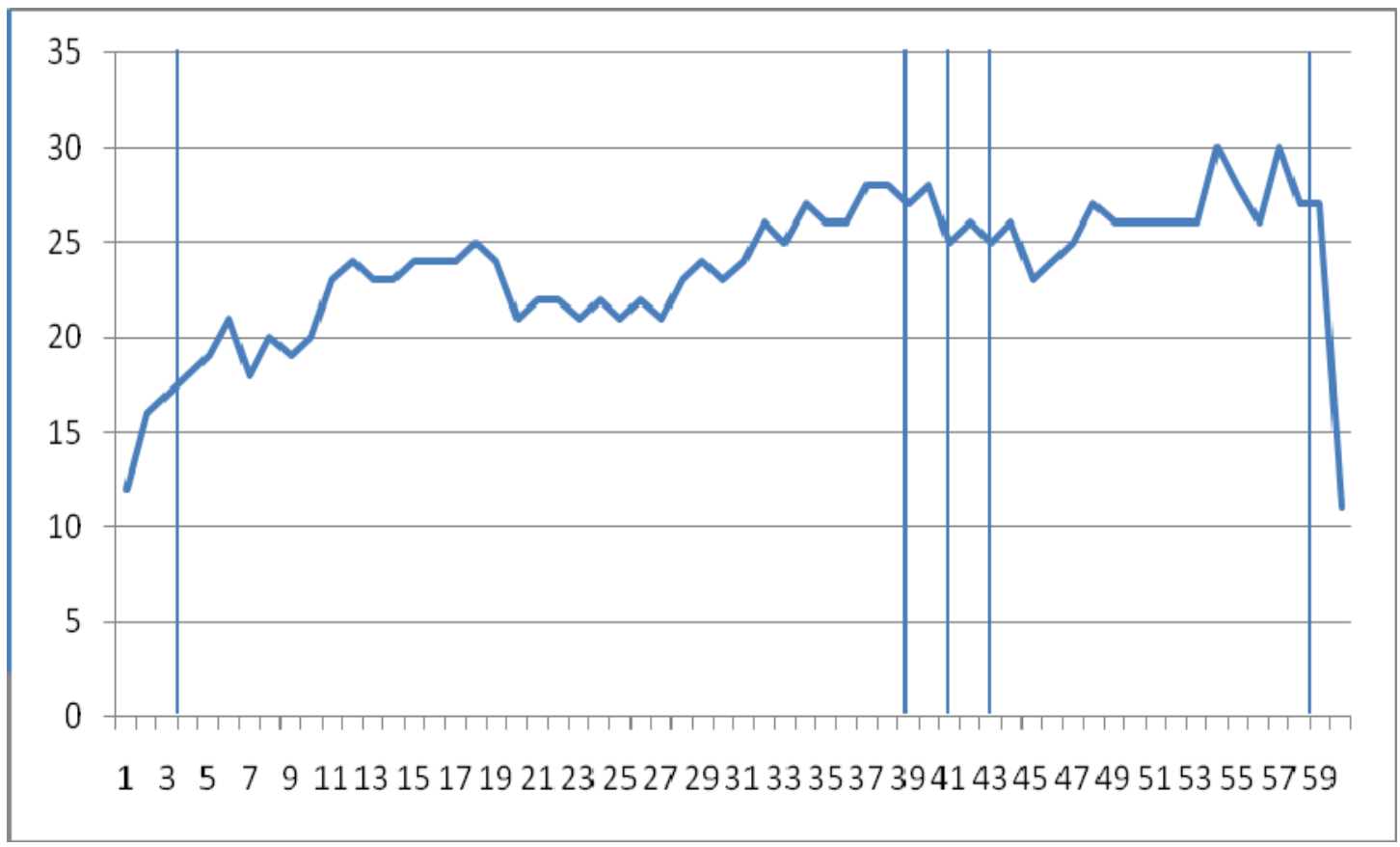

Participant 3

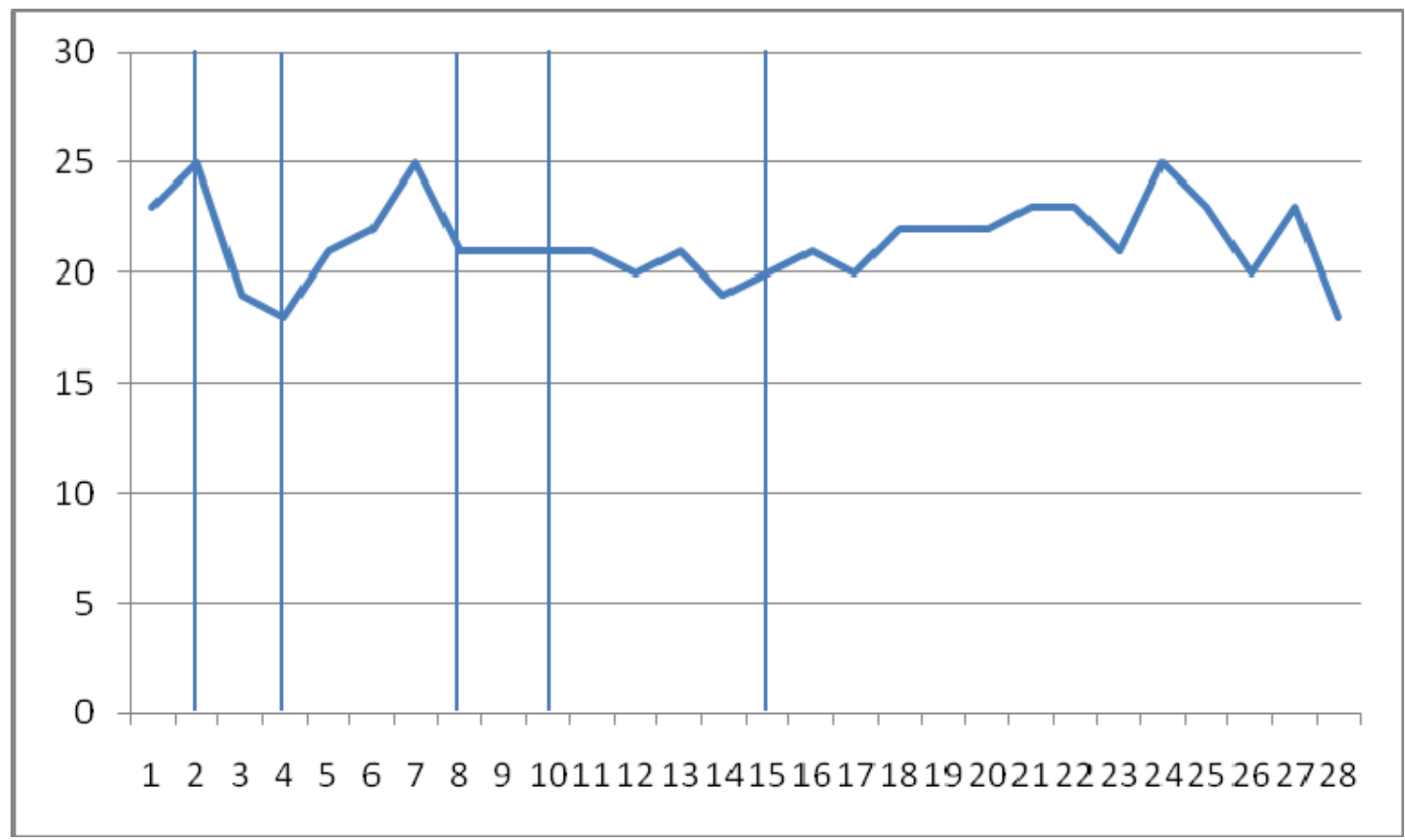

\section{Participant 4}




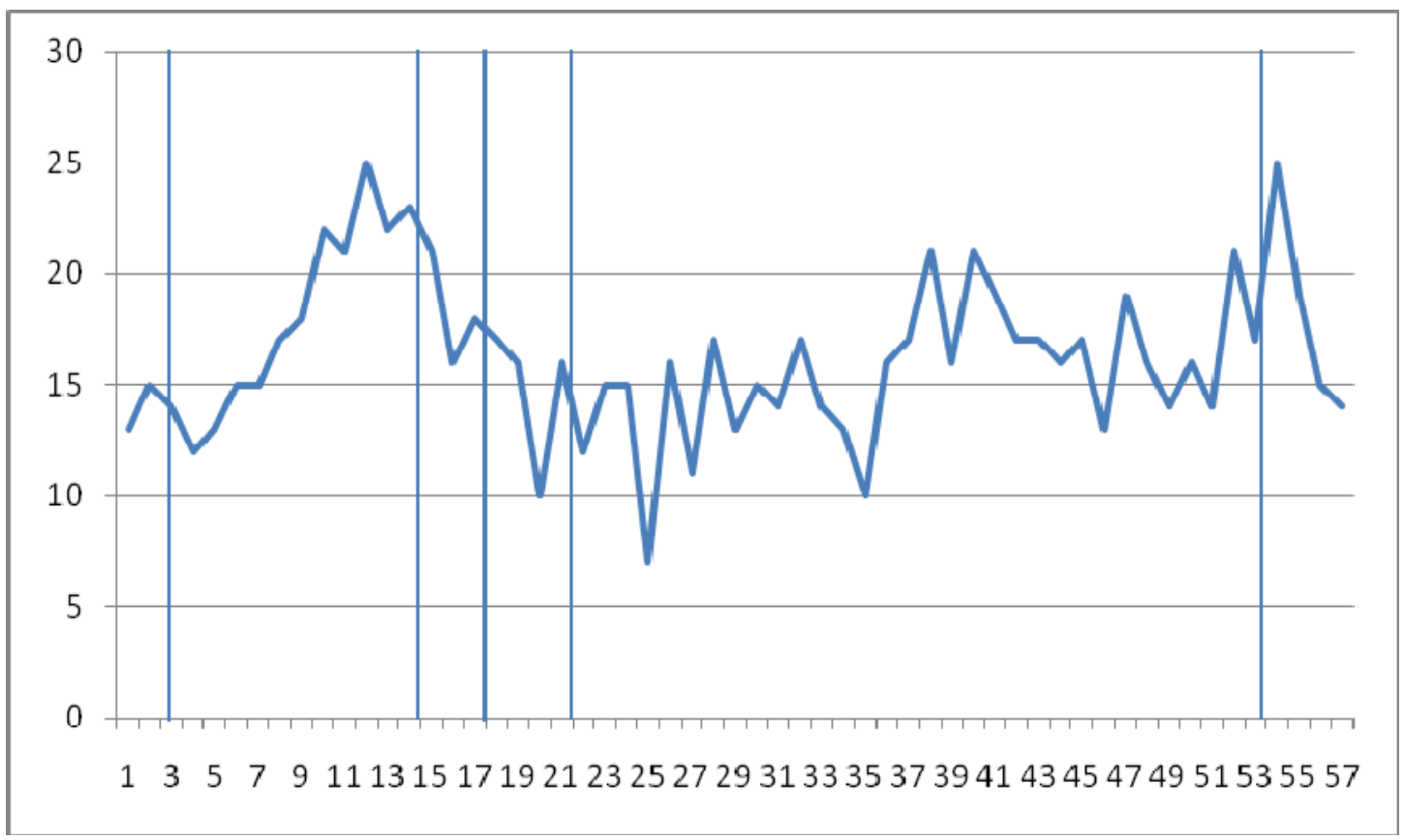

Participant 5

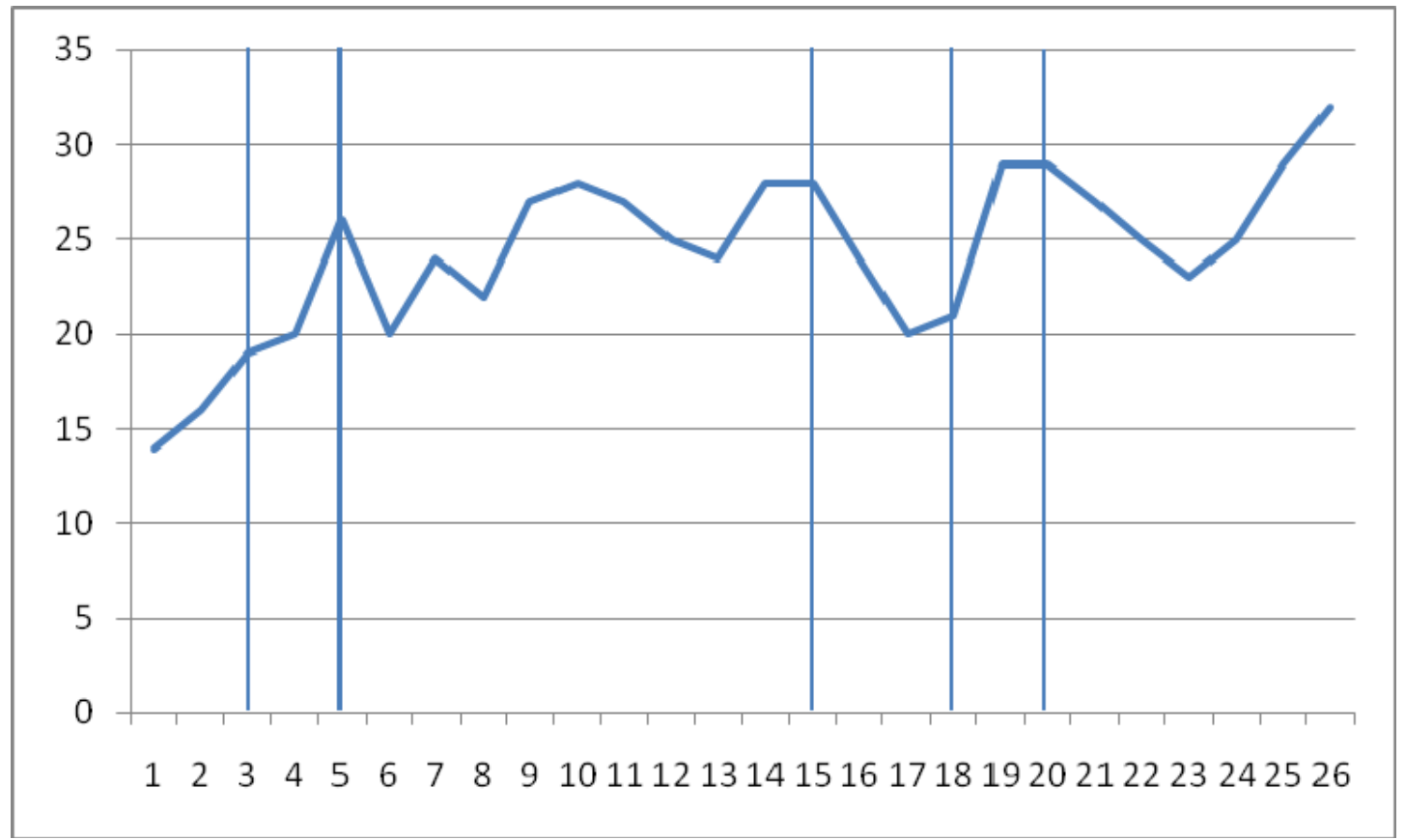

Participant 6 


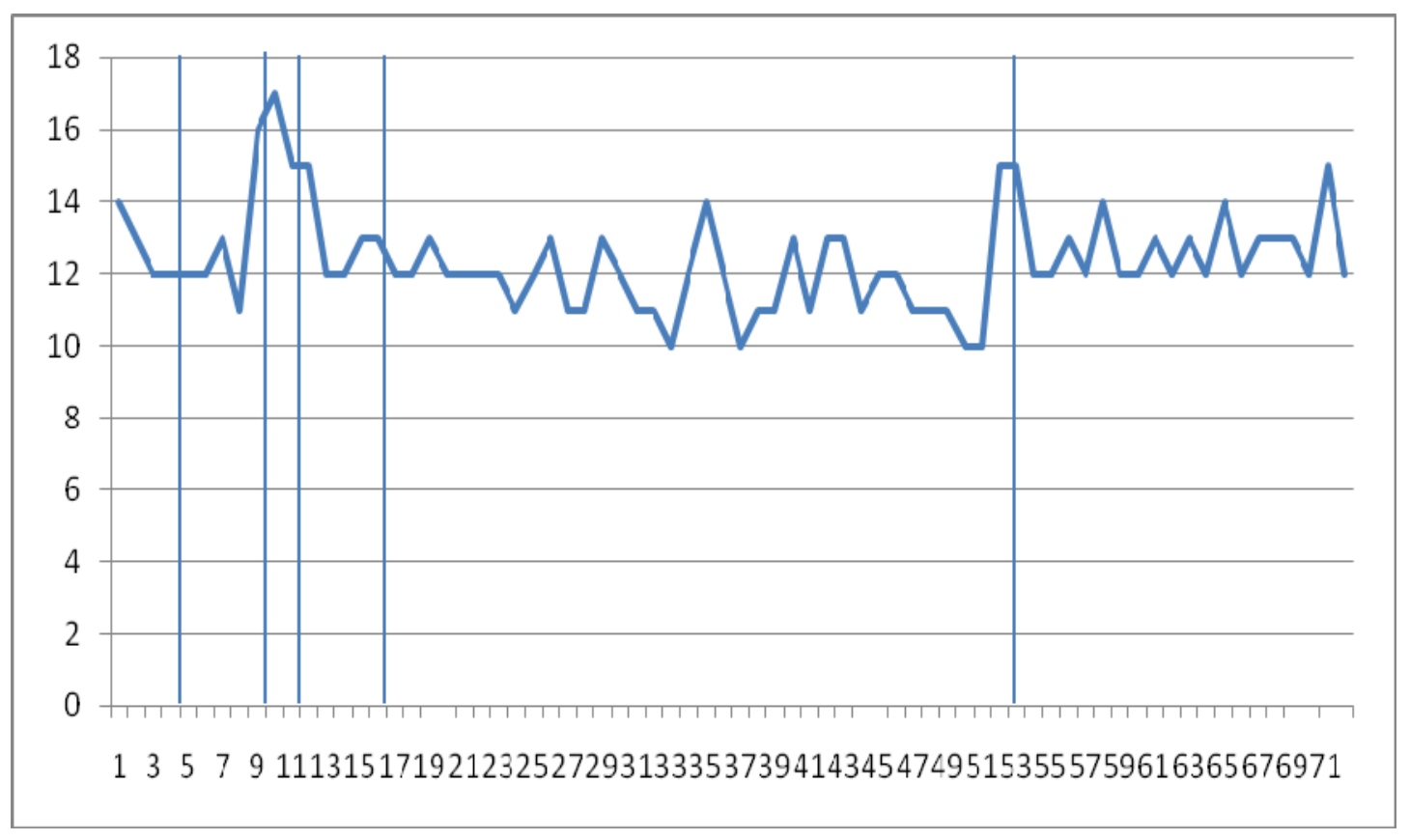

Participant 7

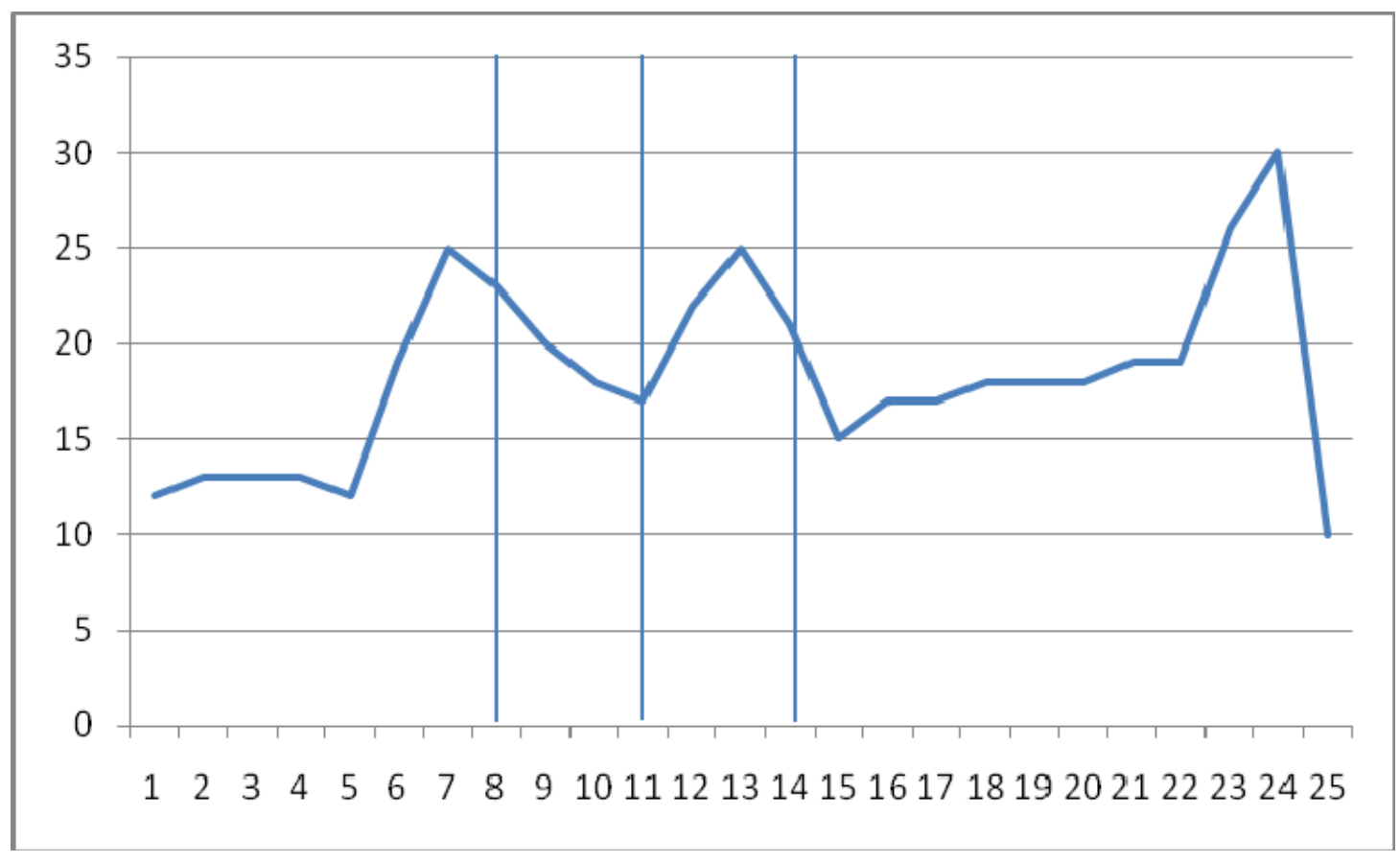

Participant 8 


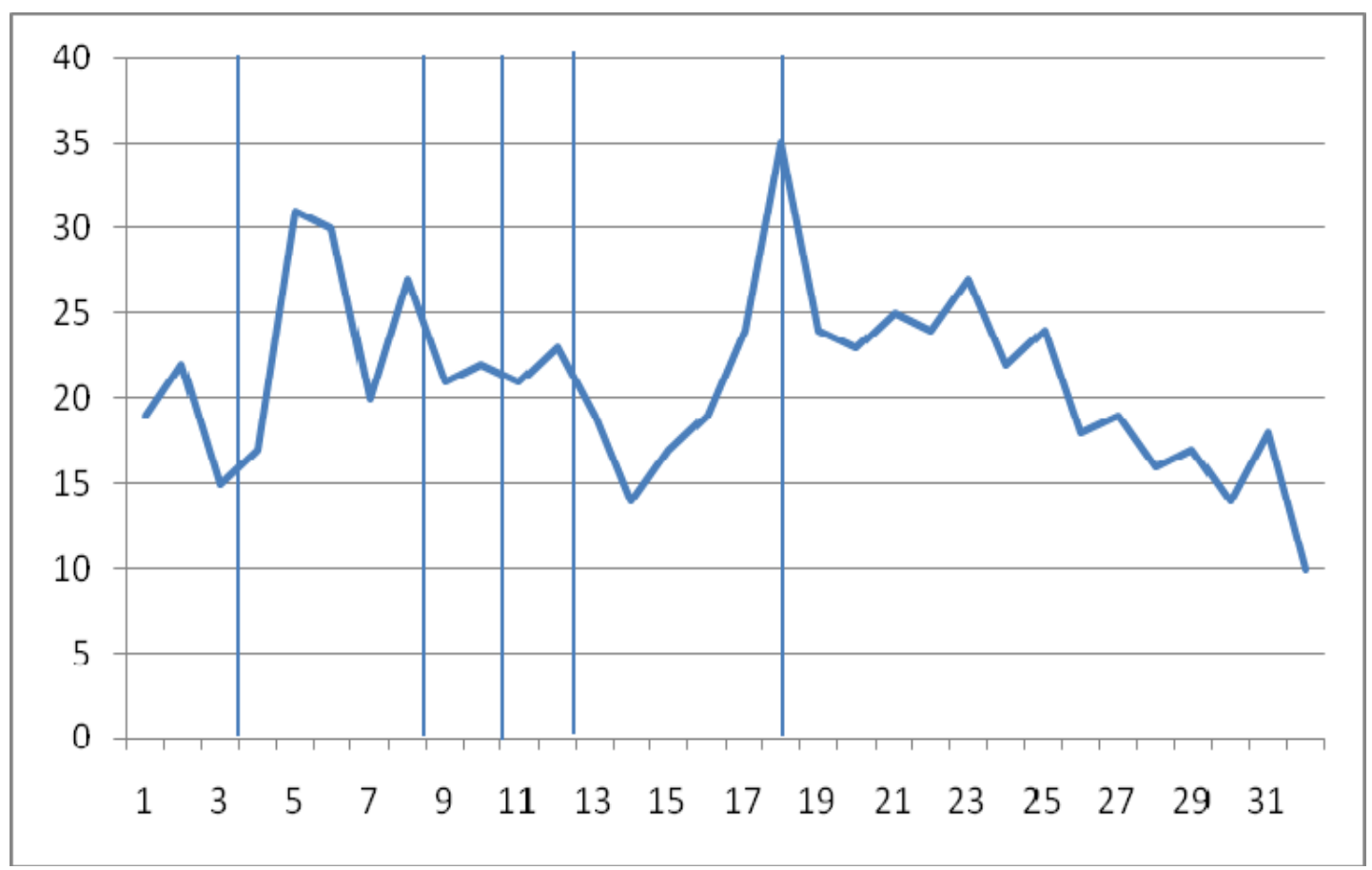

Participant 9

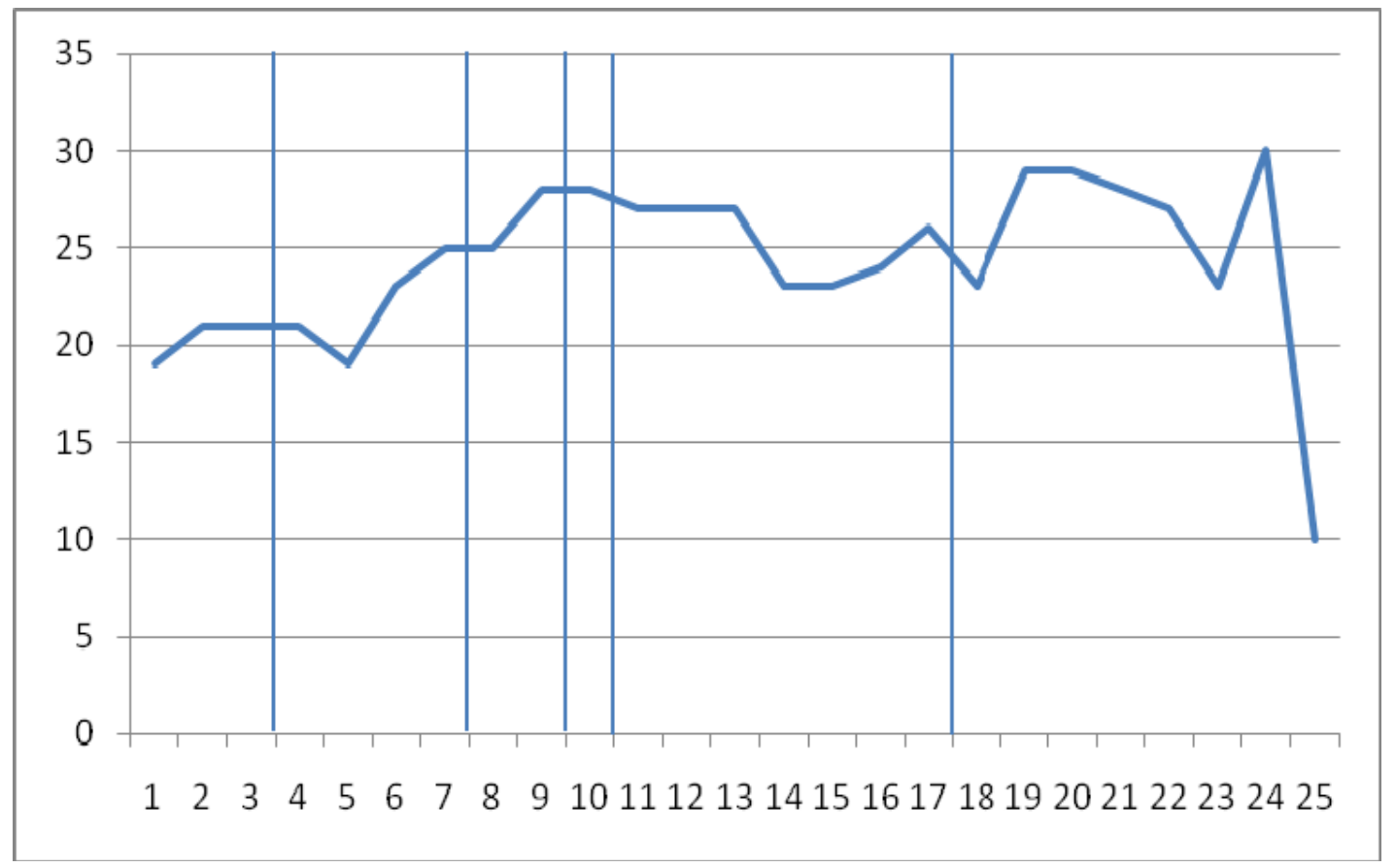

Participant 10 


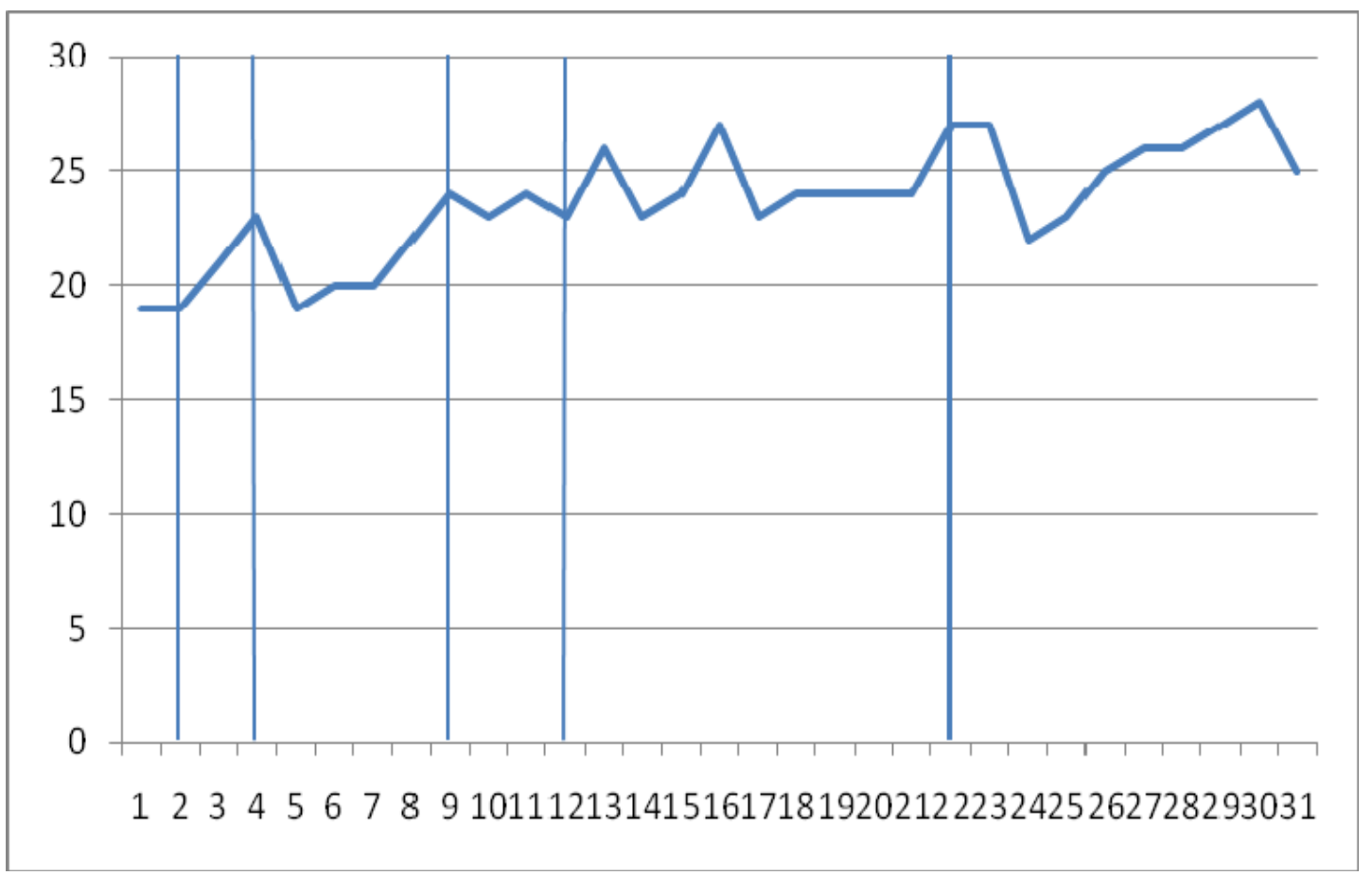

Participant 11

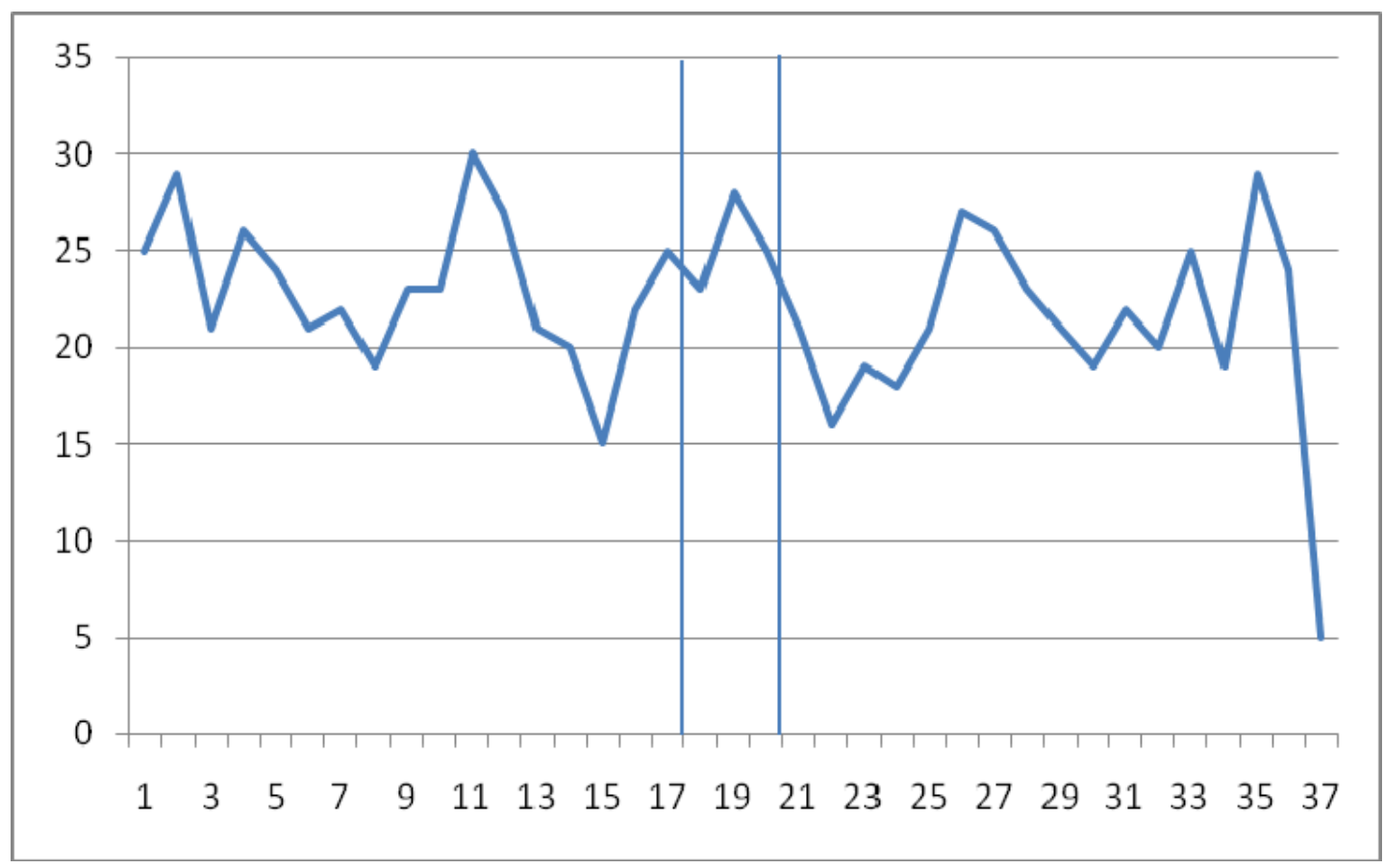

Participant 12 


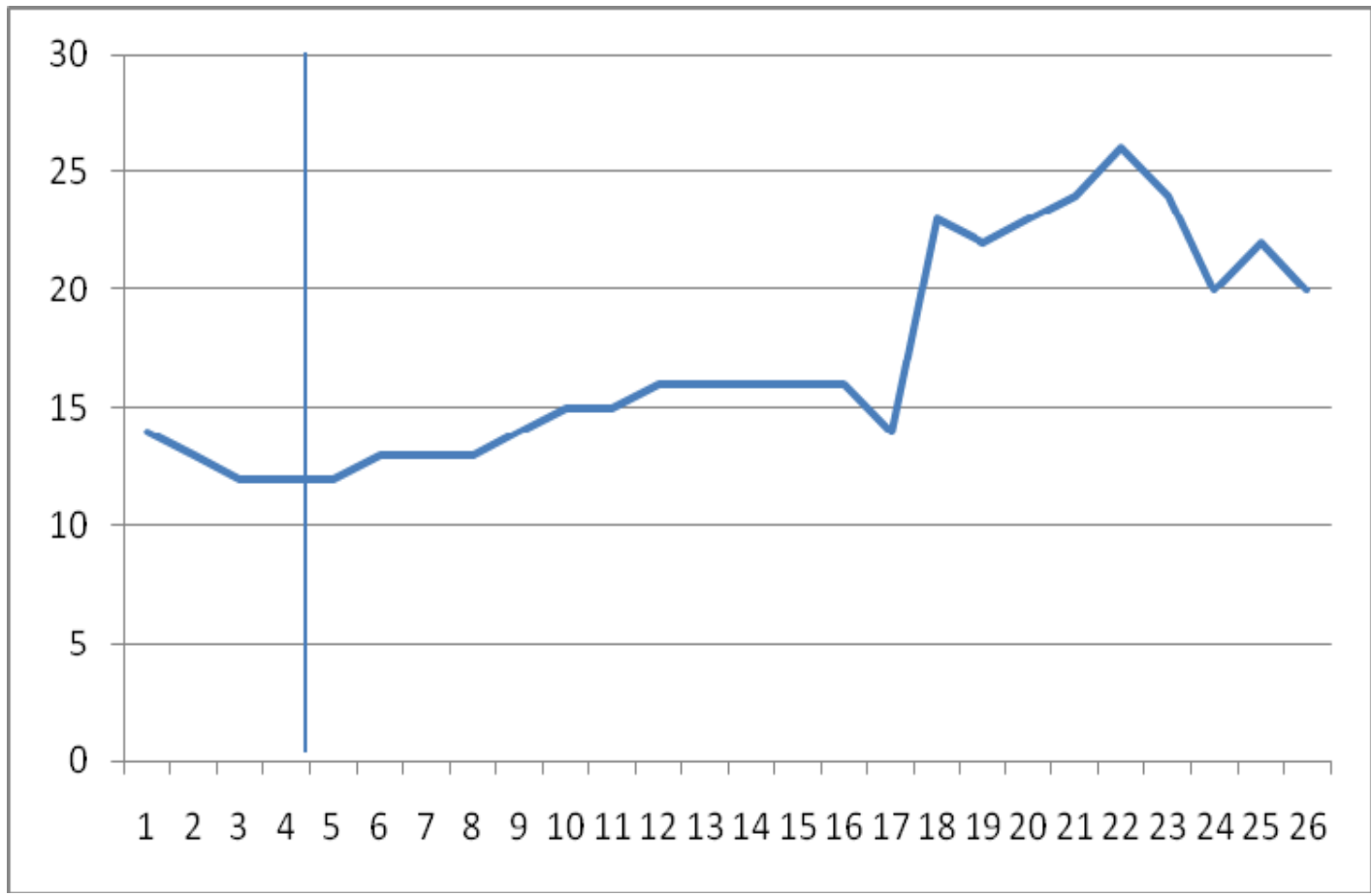

Participant 13

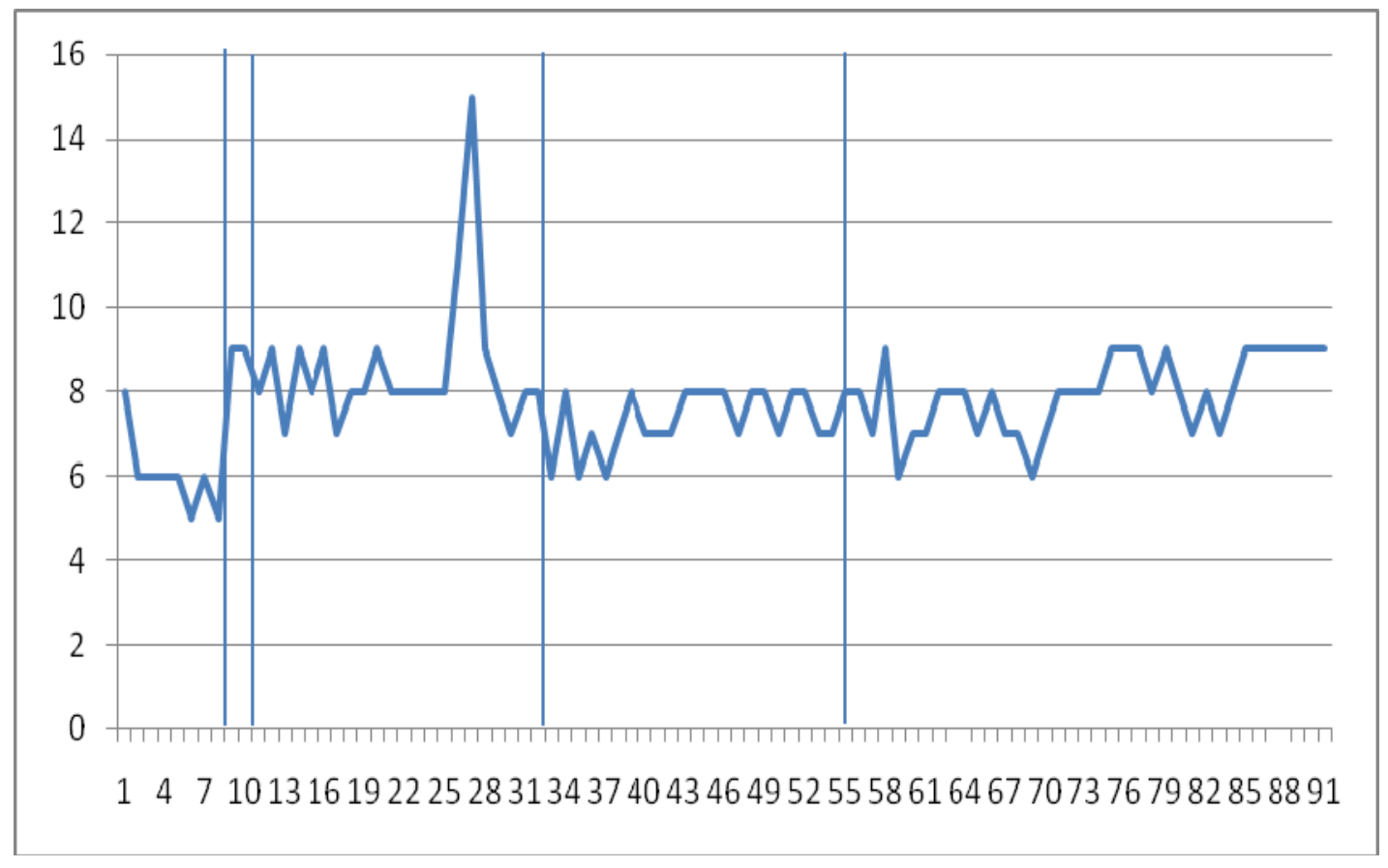

Participant 14 


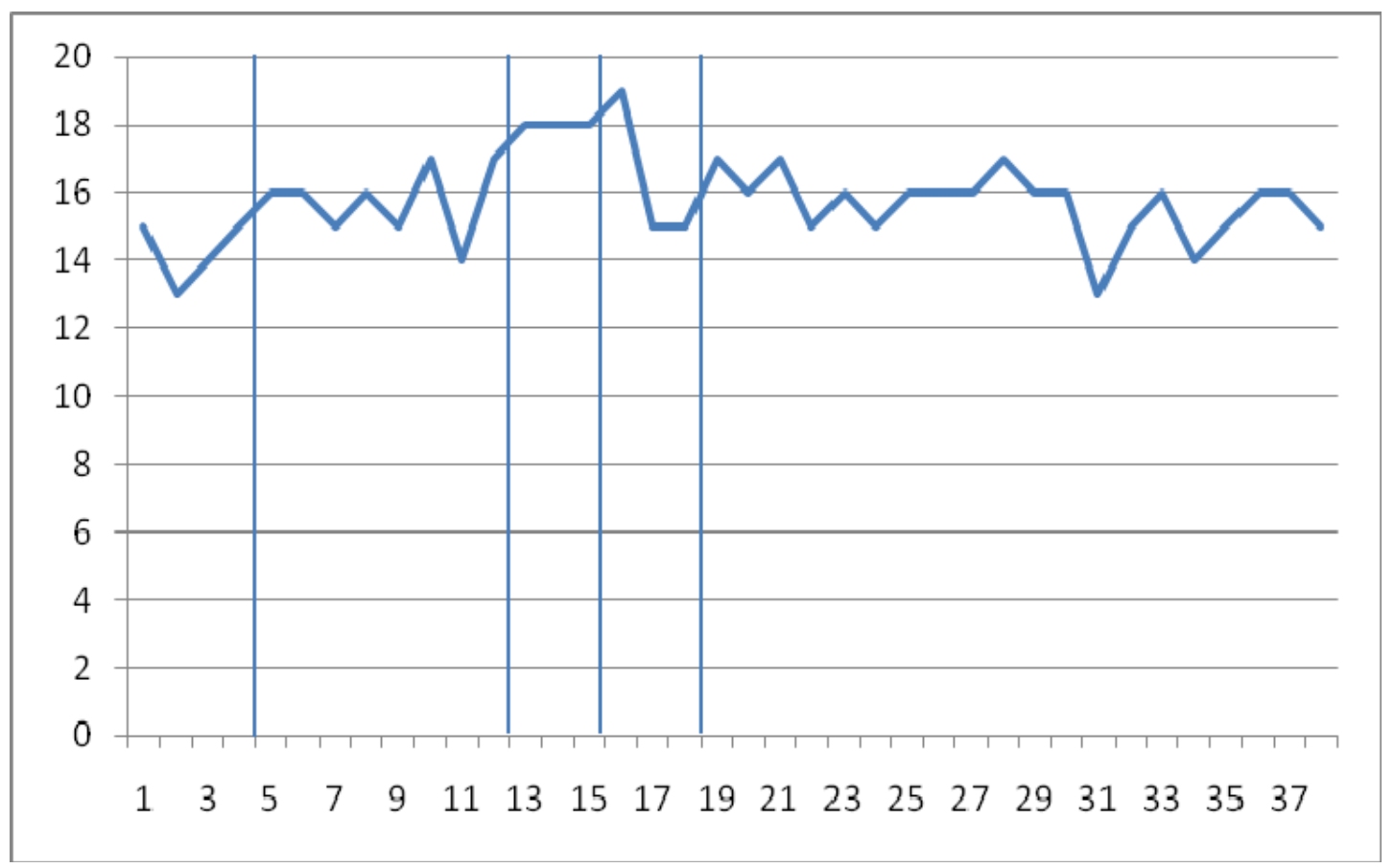

Participant 15

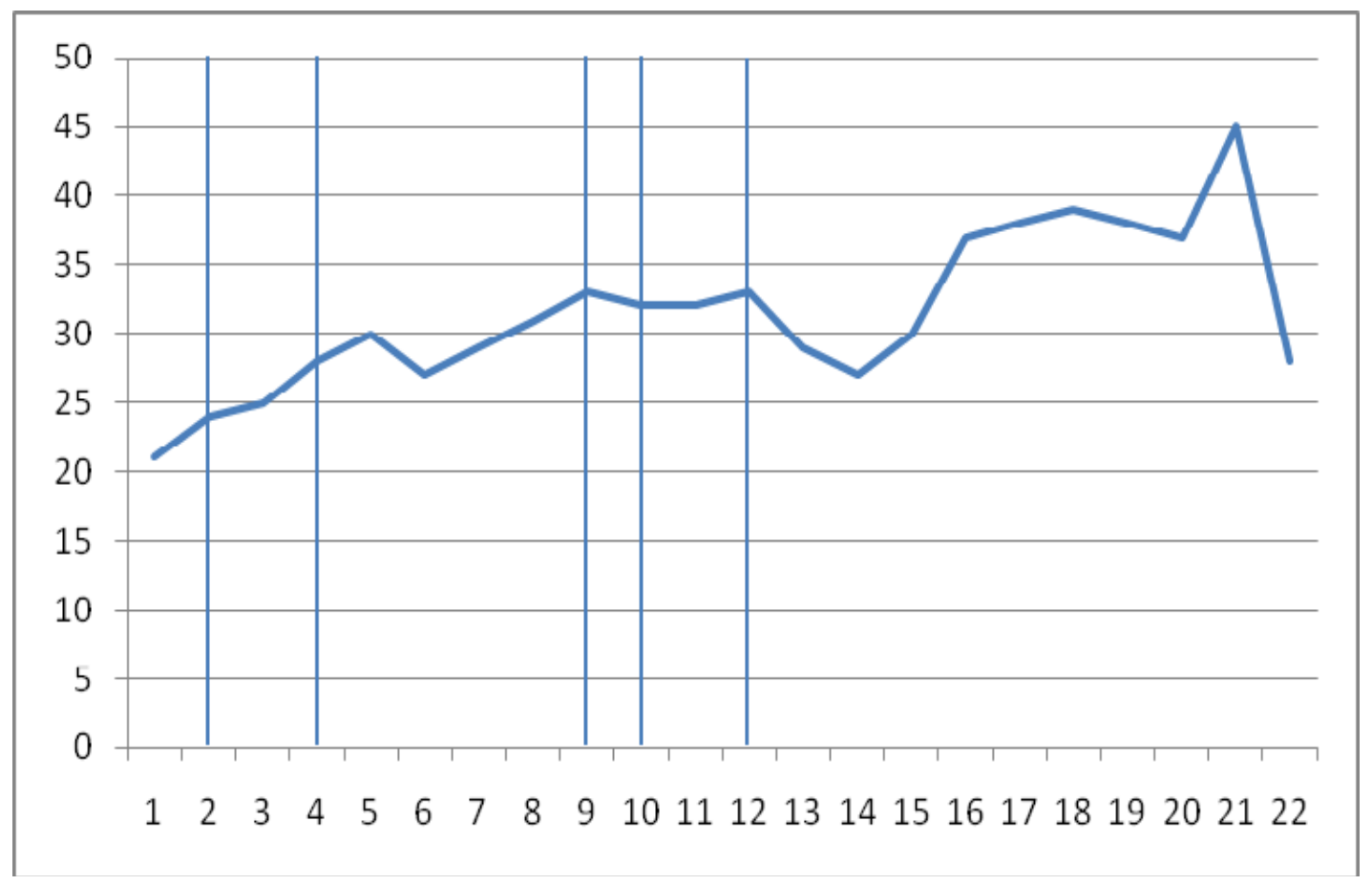

Participant 16 


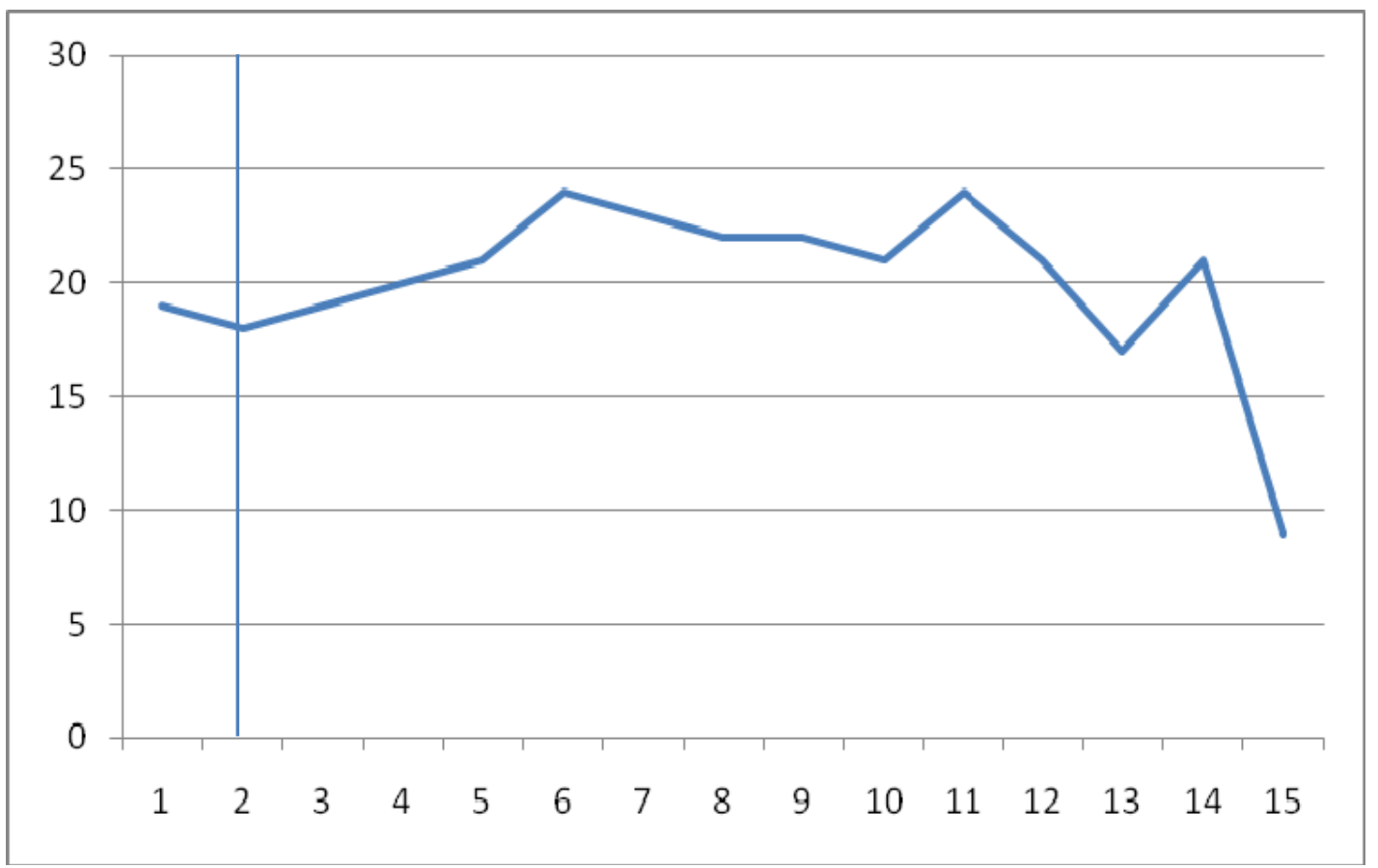

Participant 17

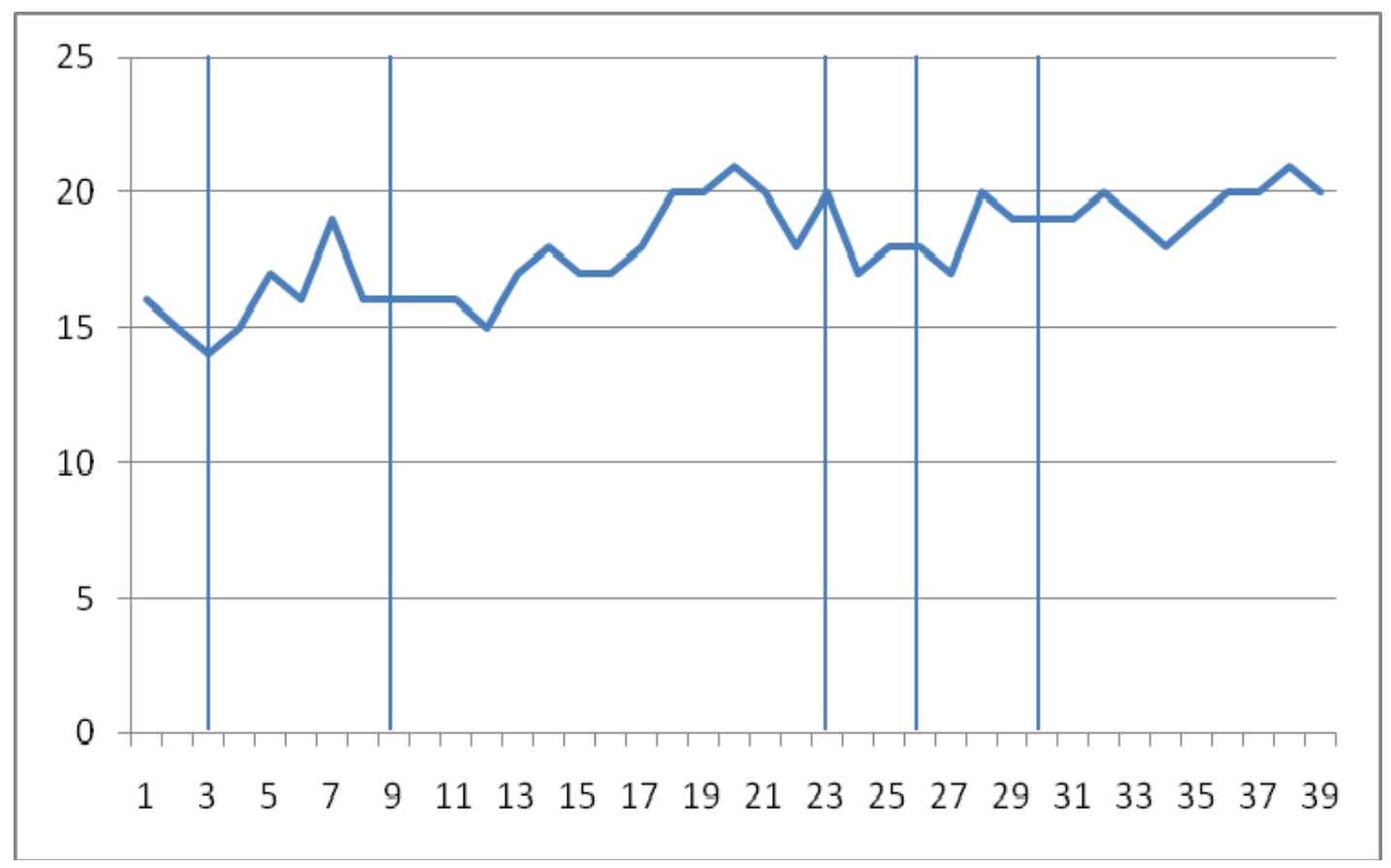

Participant 18 


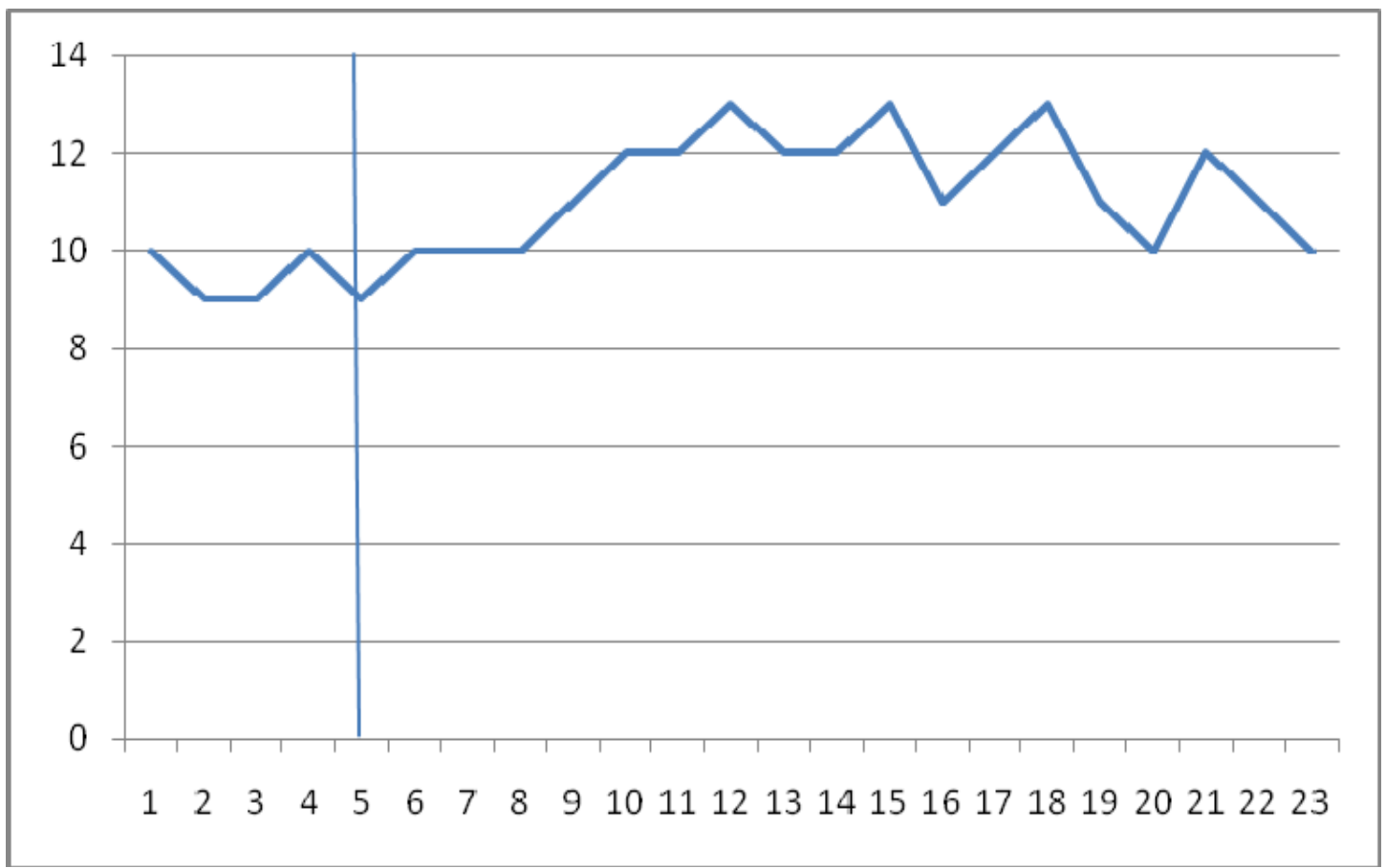

Participant 19

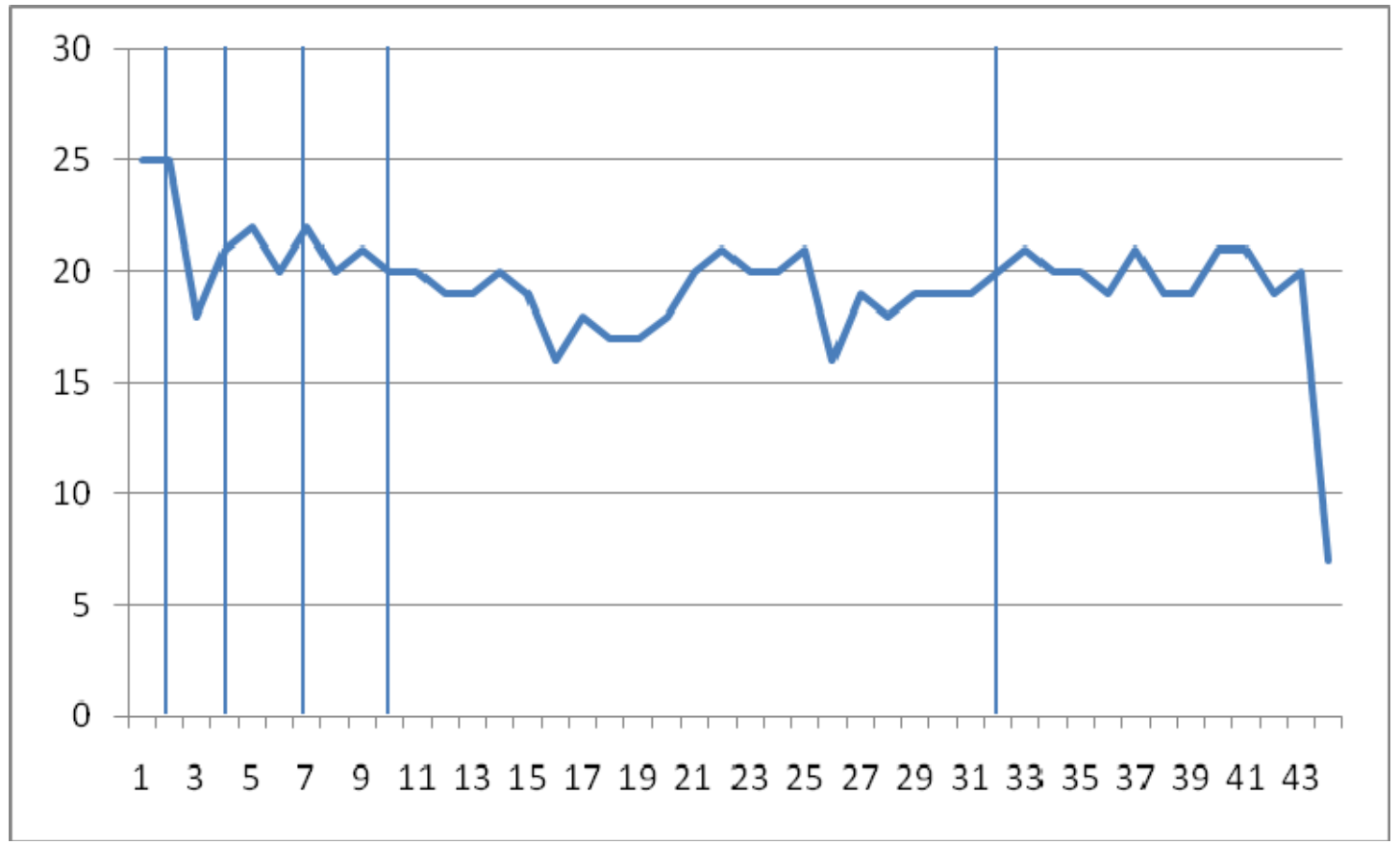

Participant 20 


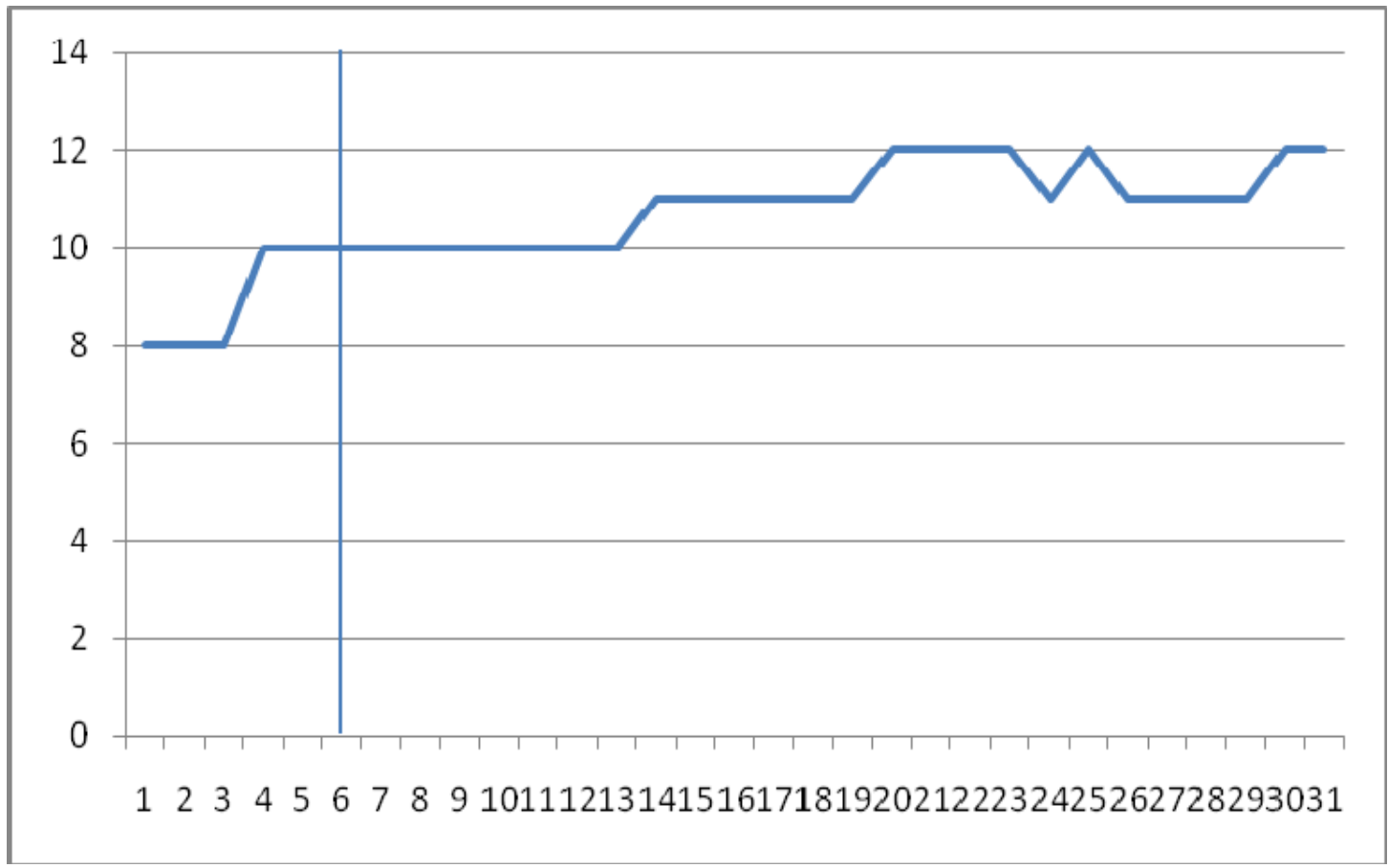

Participant 21

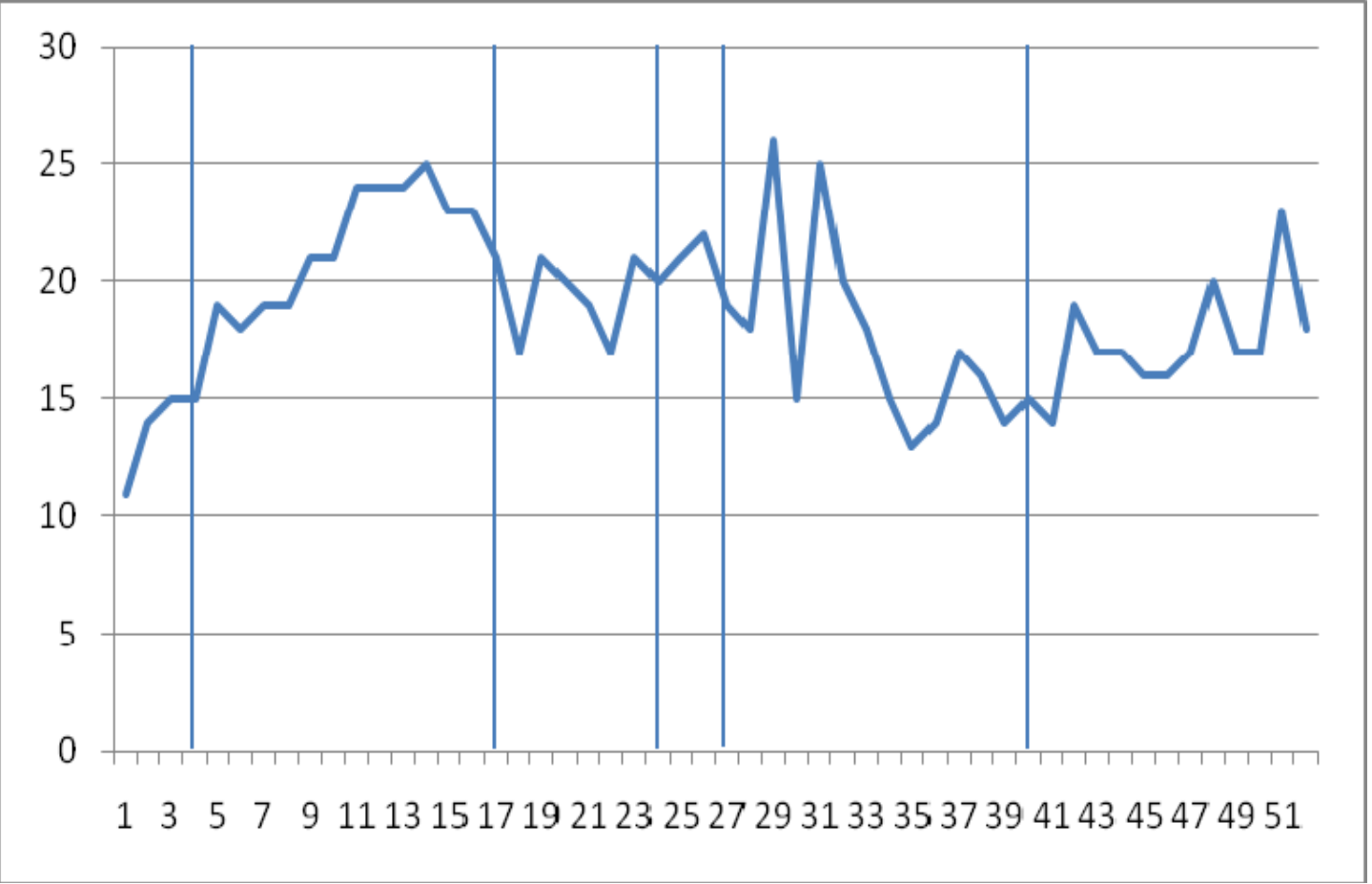

Participant 22 


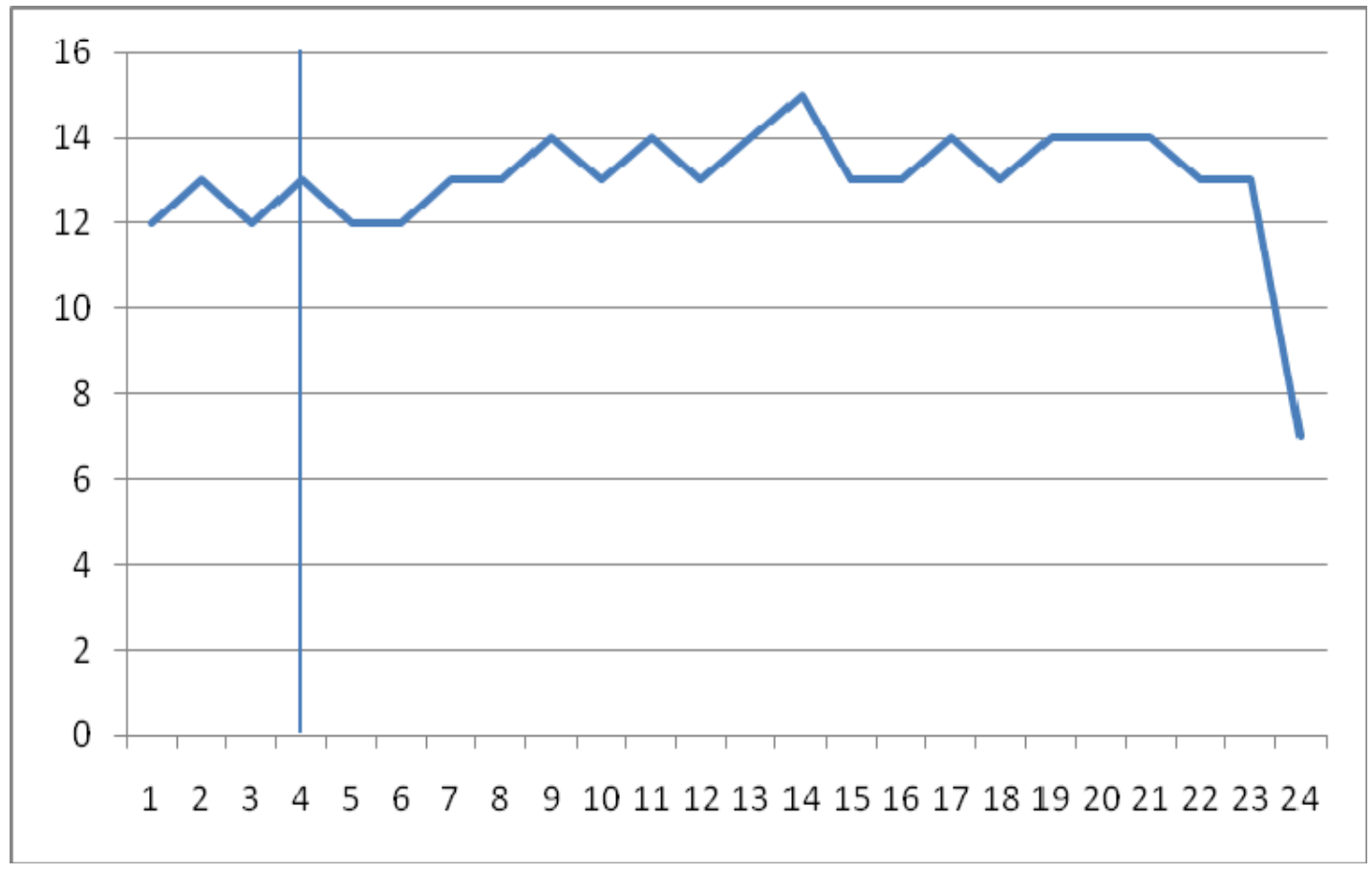

Participant 23

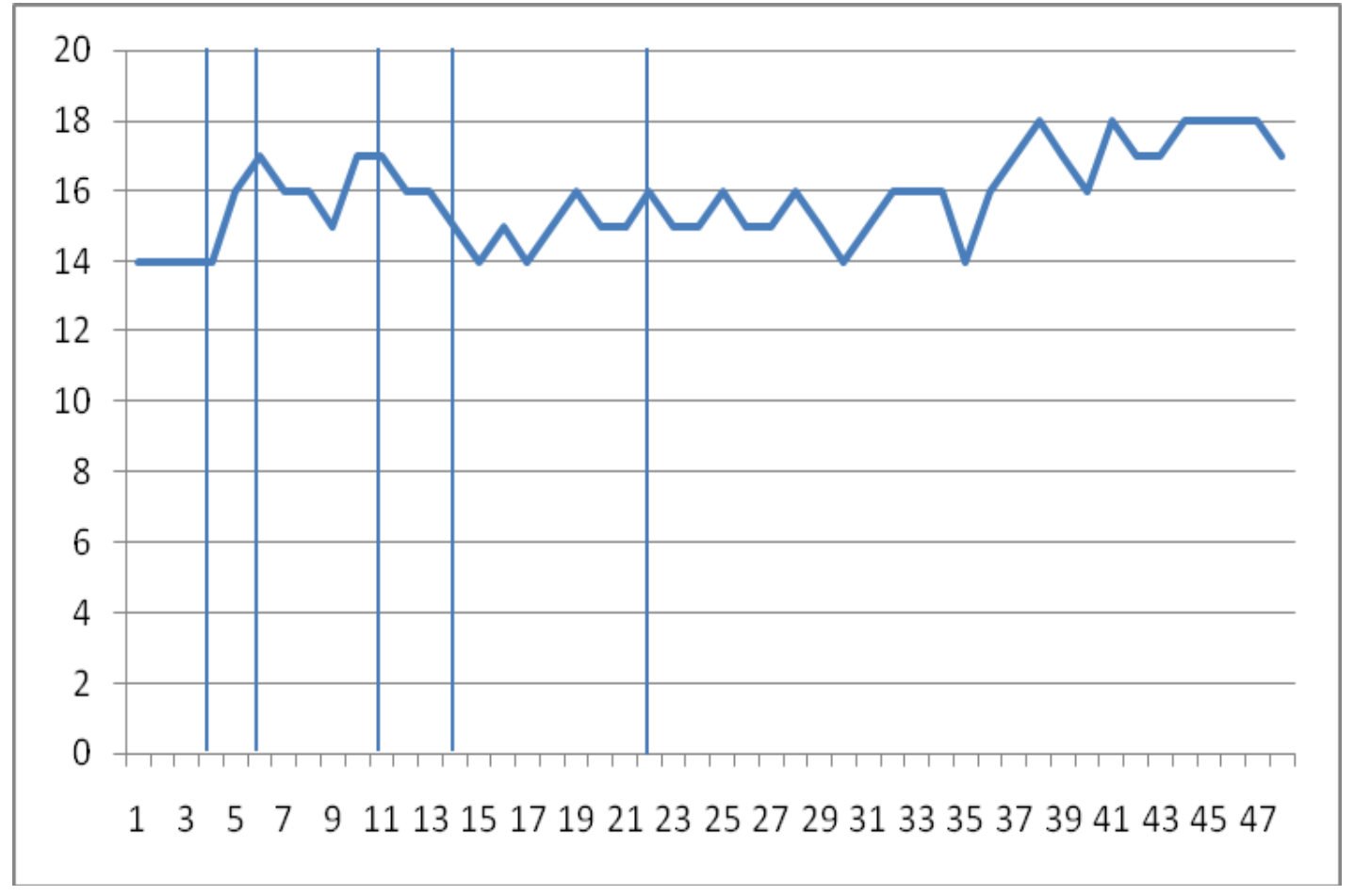

Participant 24 


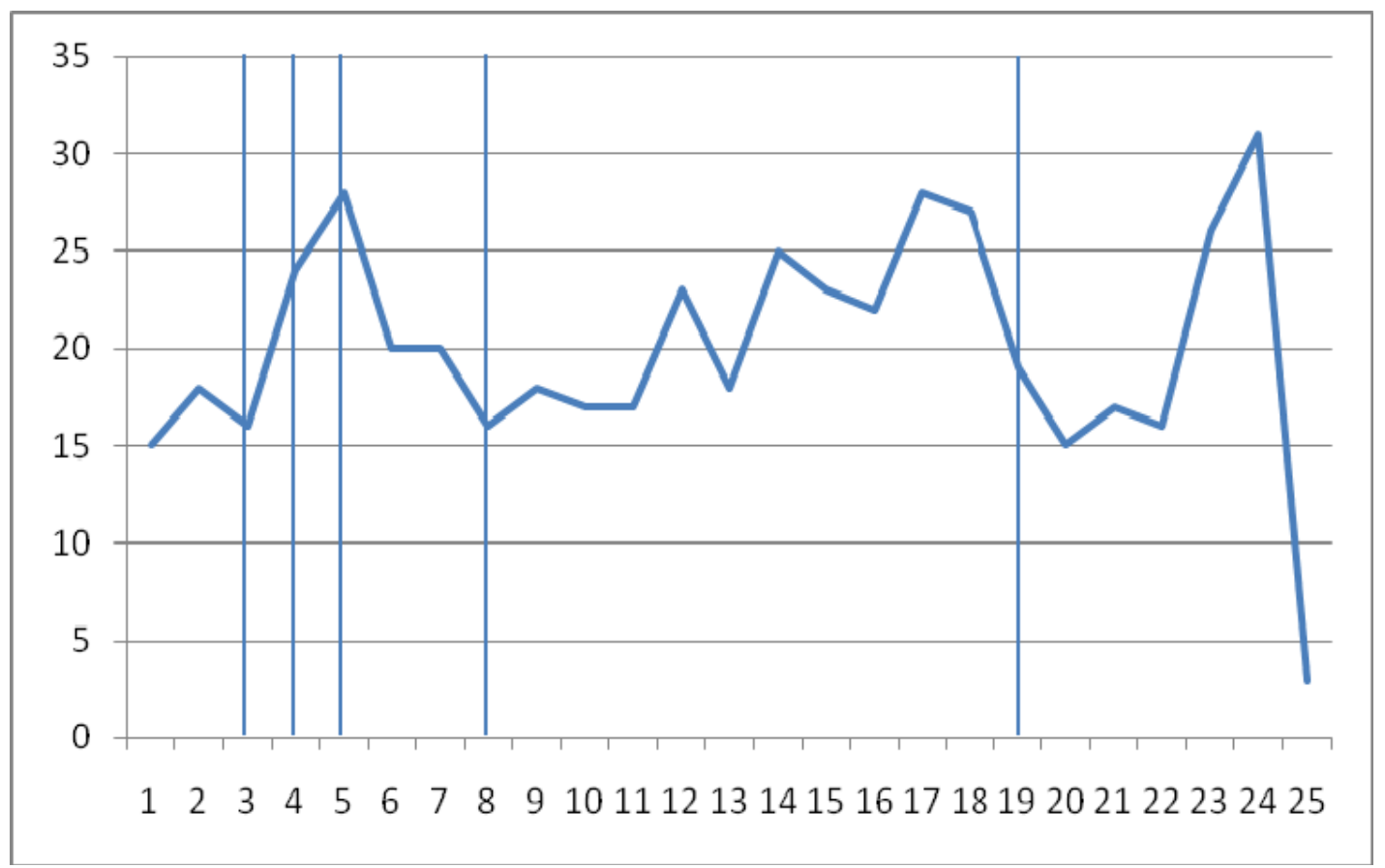

Participant 25

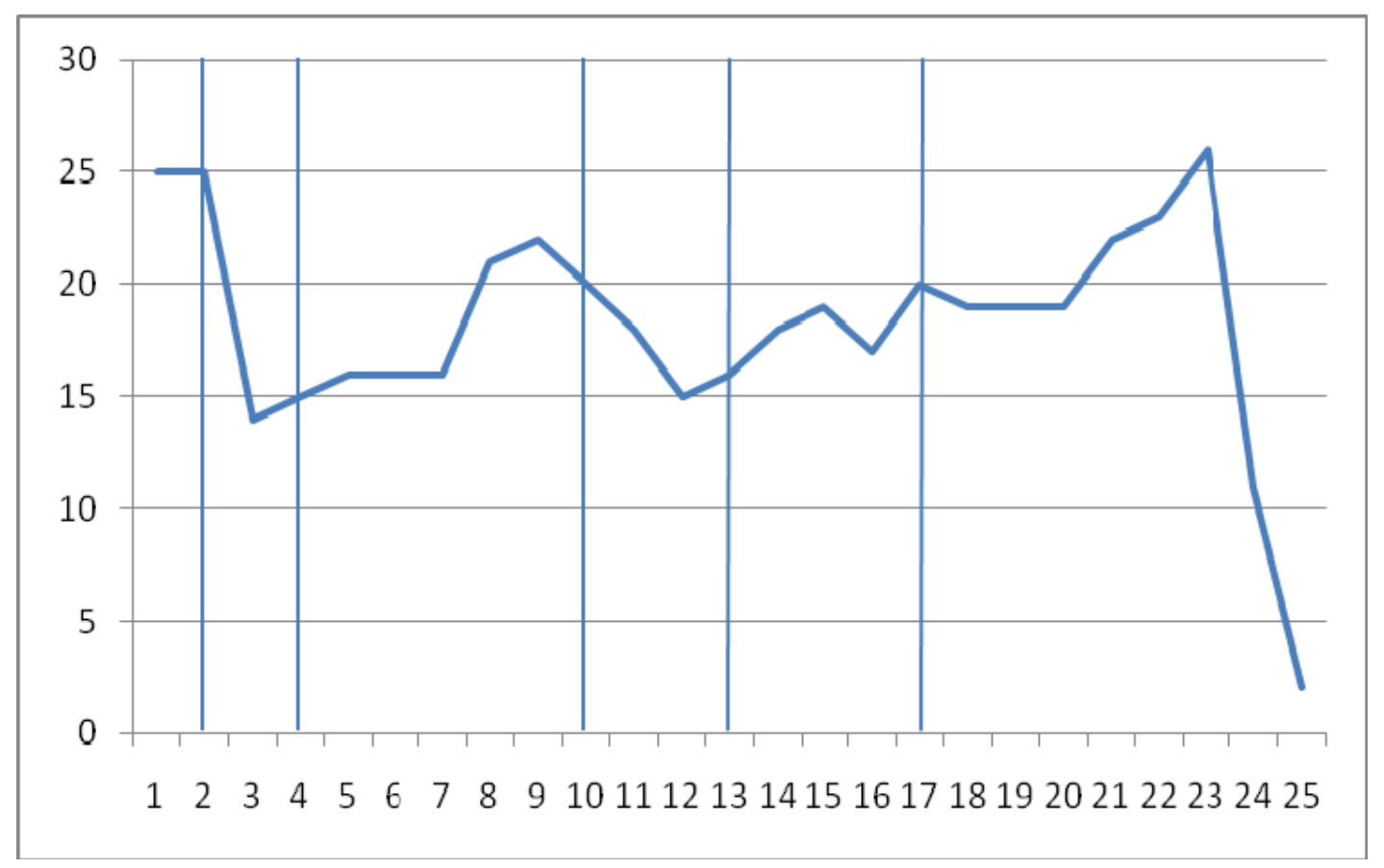

Participant 26 


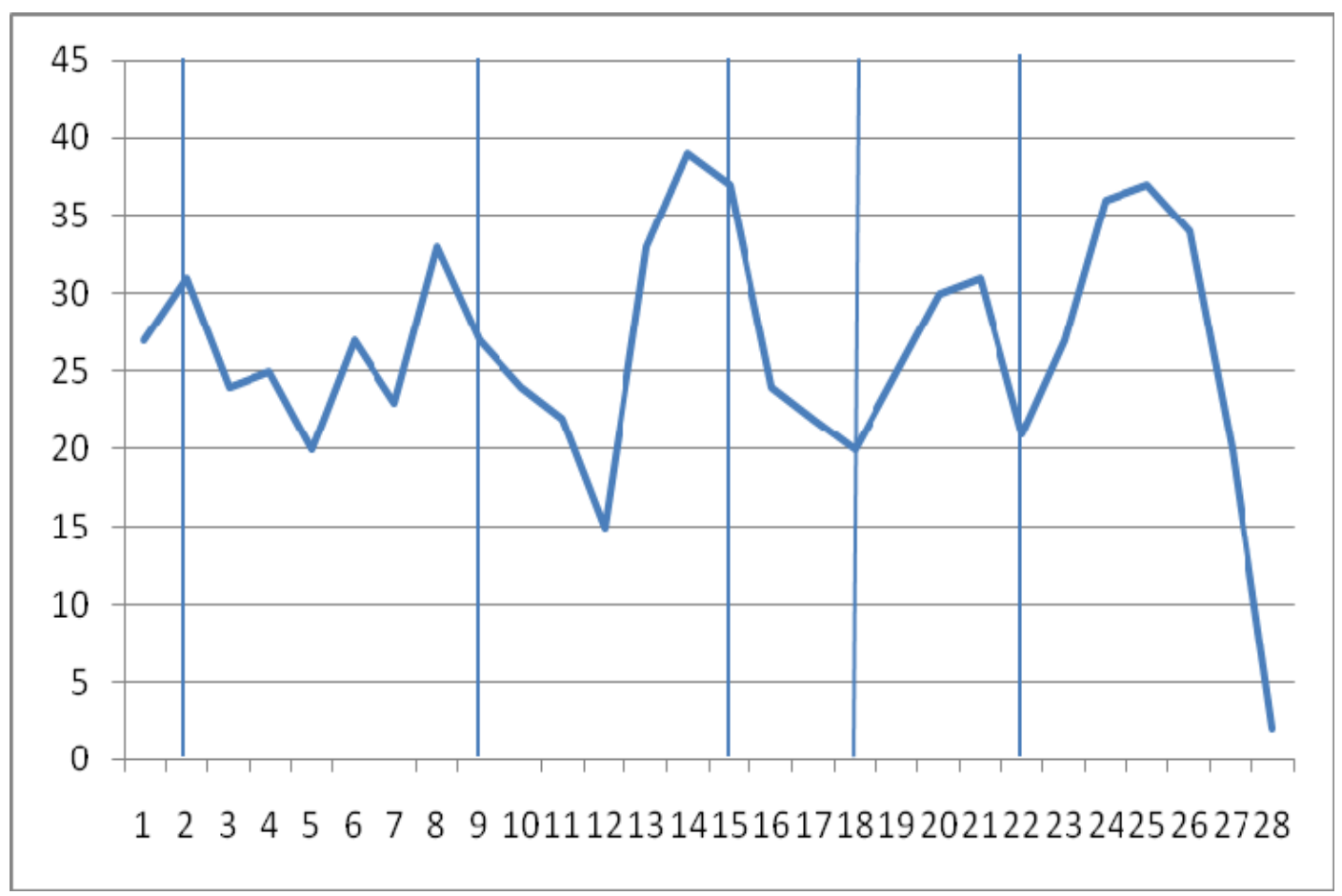

Participant 27

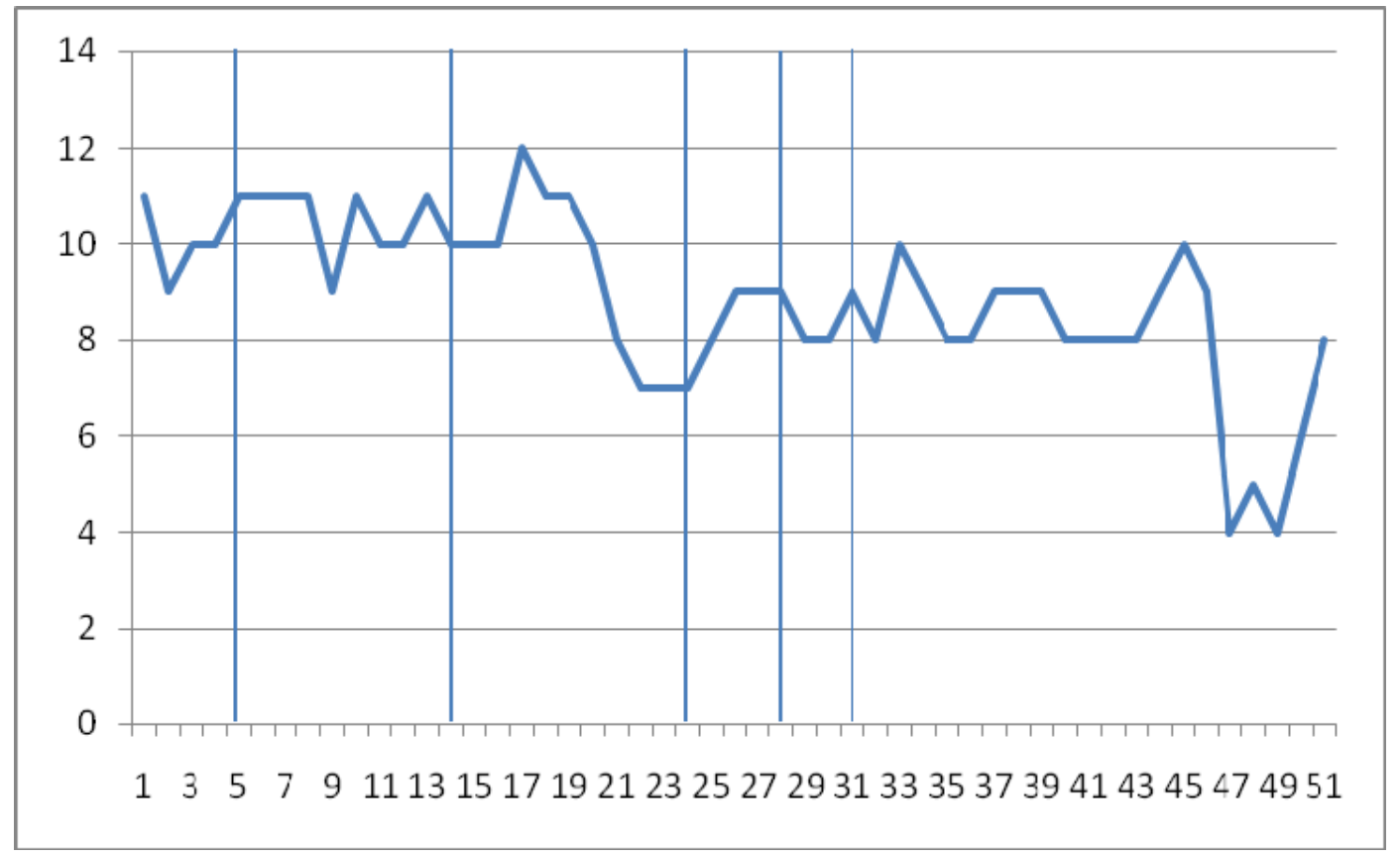

Participant 28 


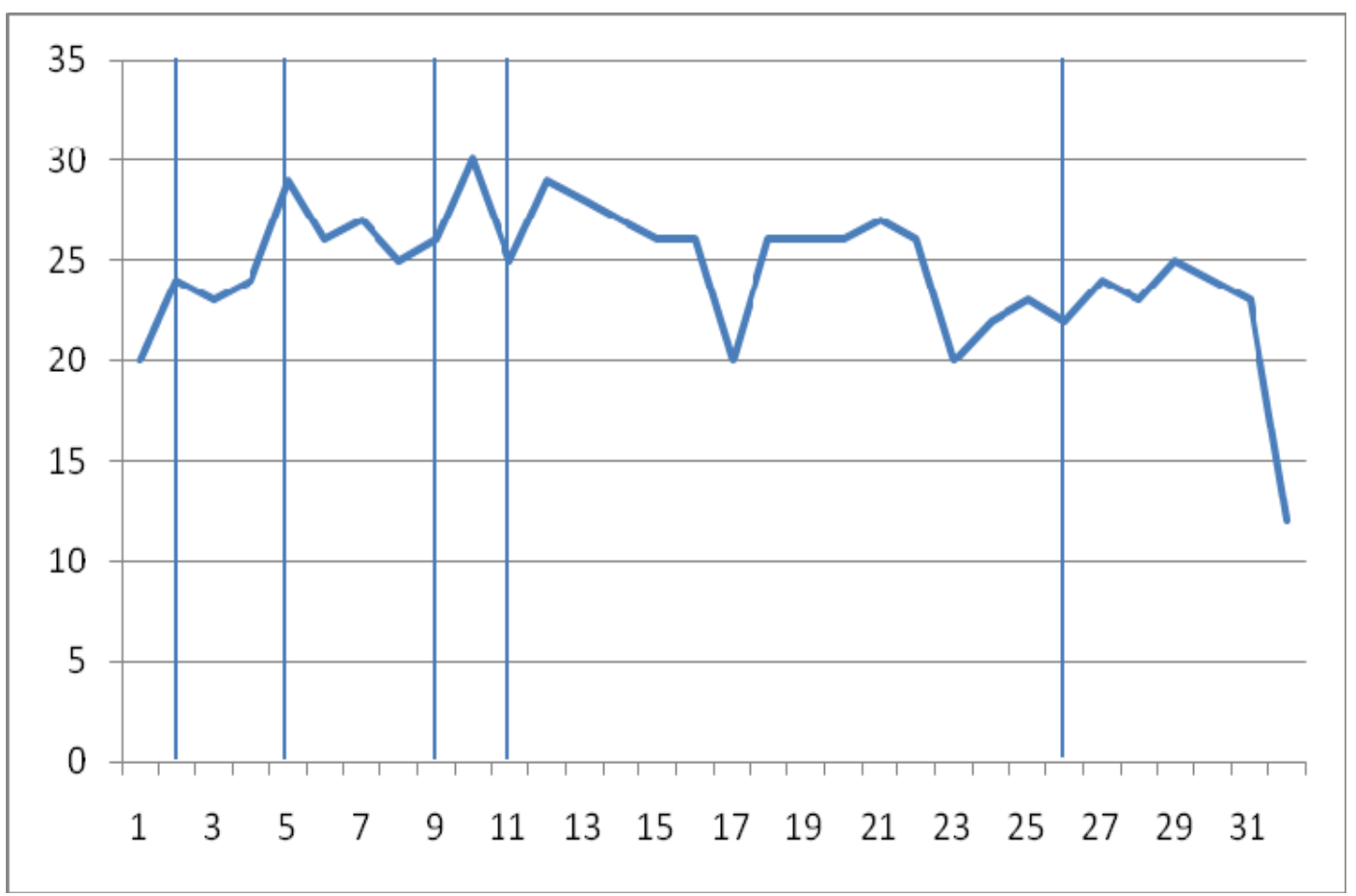

Participant 29

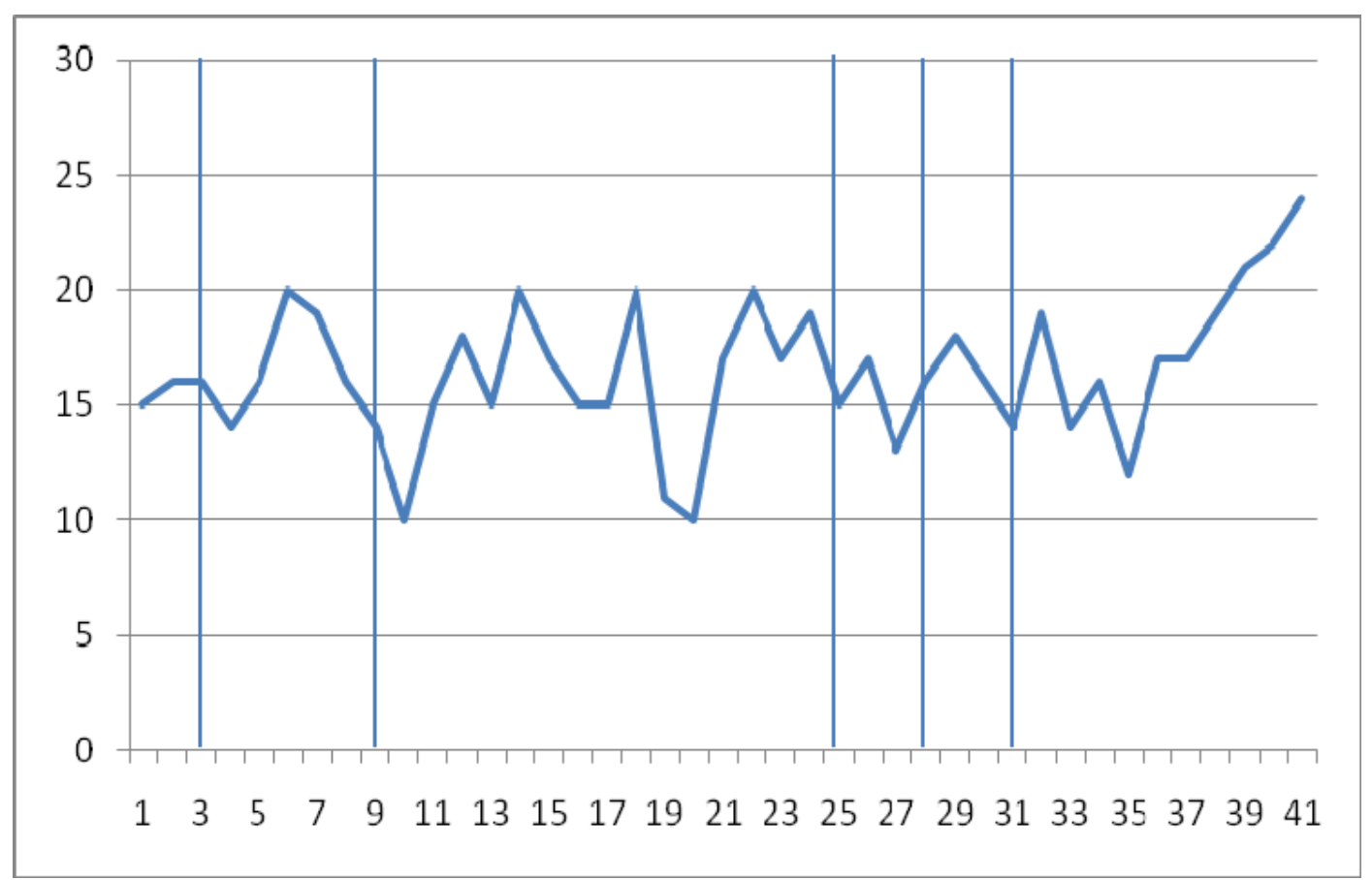

Participant 30 
Trials-to-criterion: When multipletask is presented first

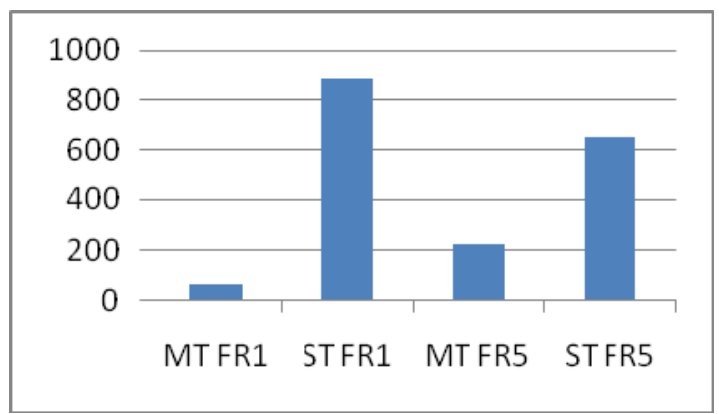

Participant 2

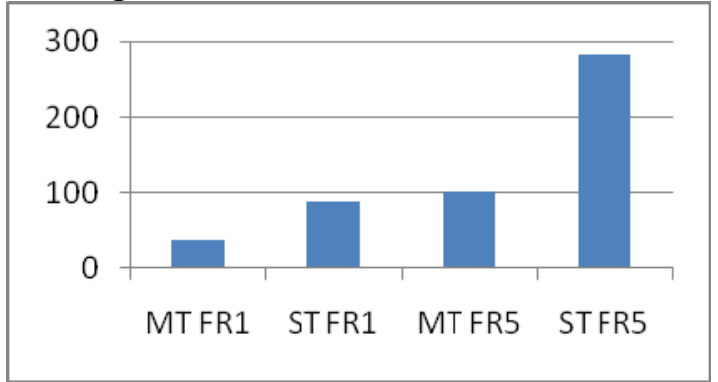

Participant 4

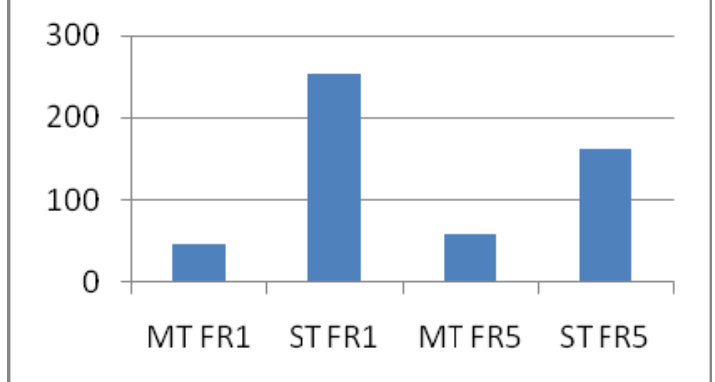

\section{Participant6}

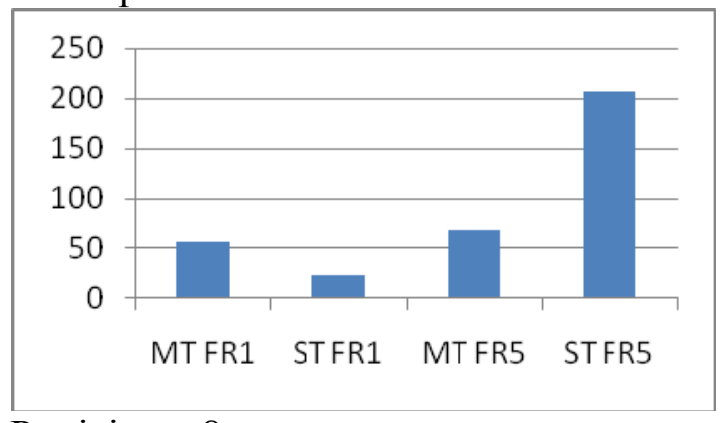

Participant 8

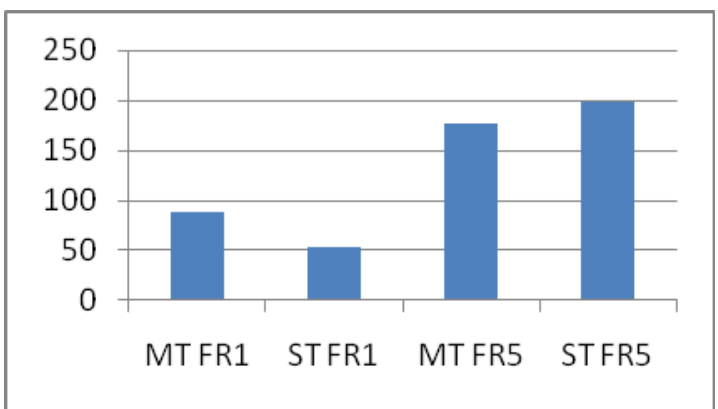

\section{Participant 10}

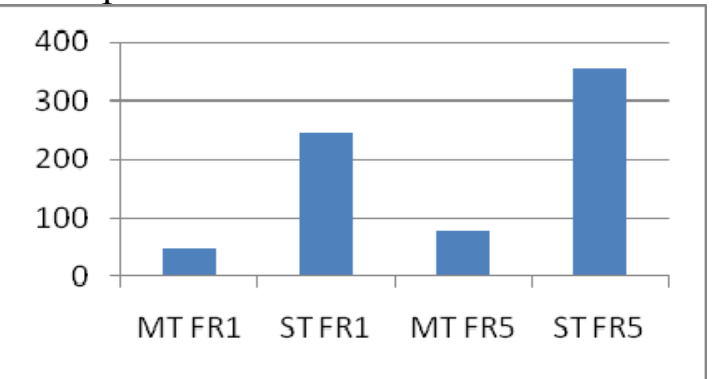

Participant 12

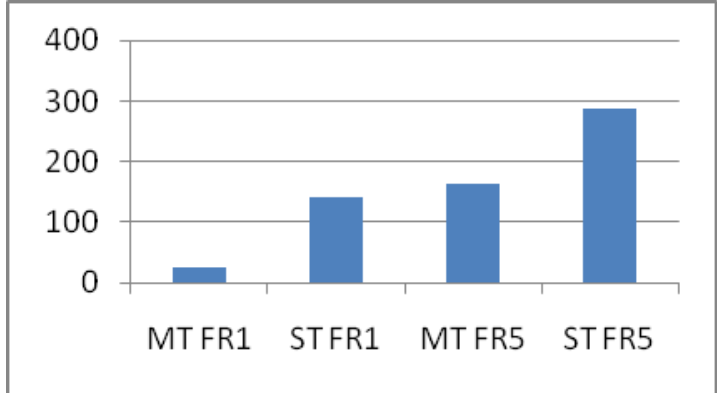

Participant 14

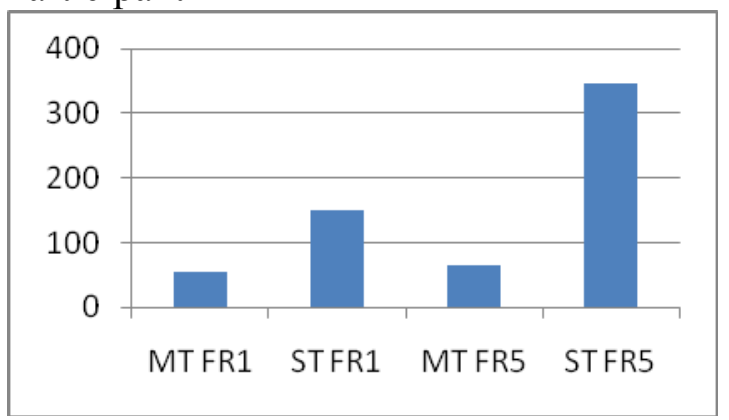

Participant 16 


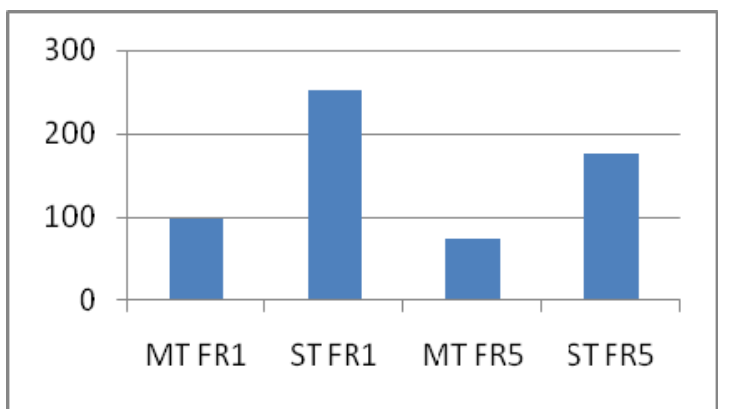

Participant 18

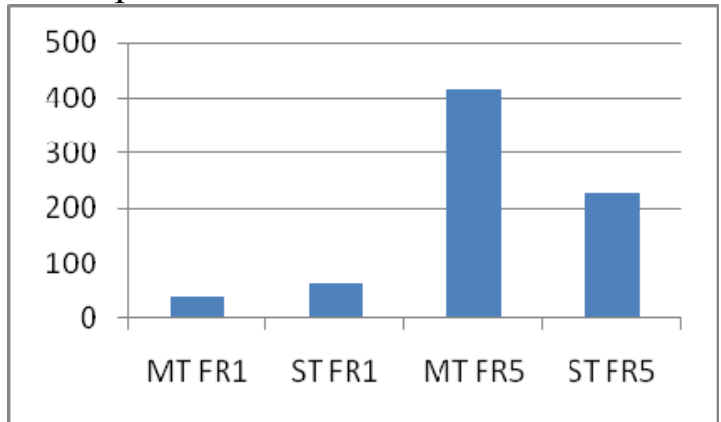

Participant 20

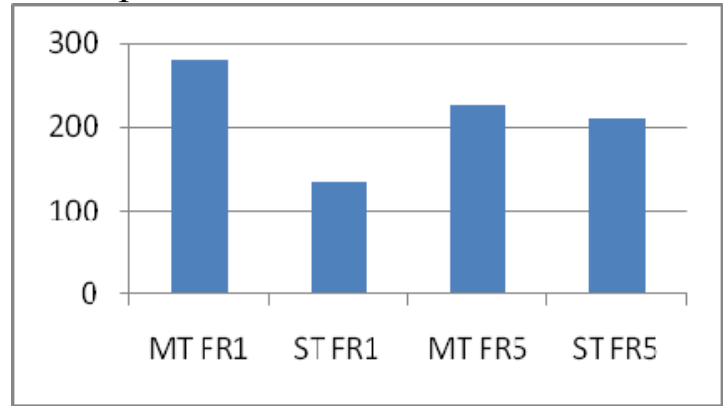

\section{Participant 22}

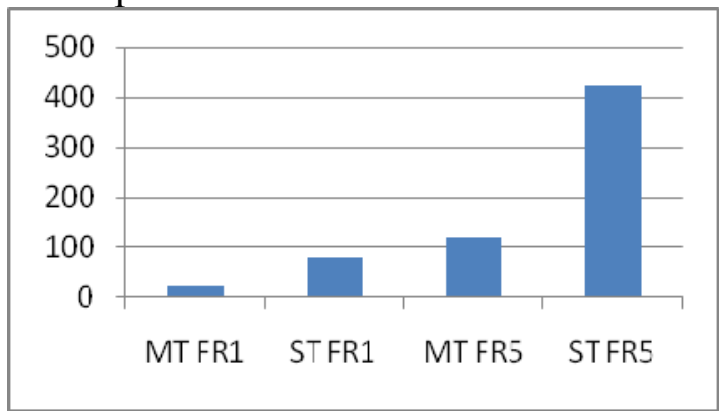

Participant 24

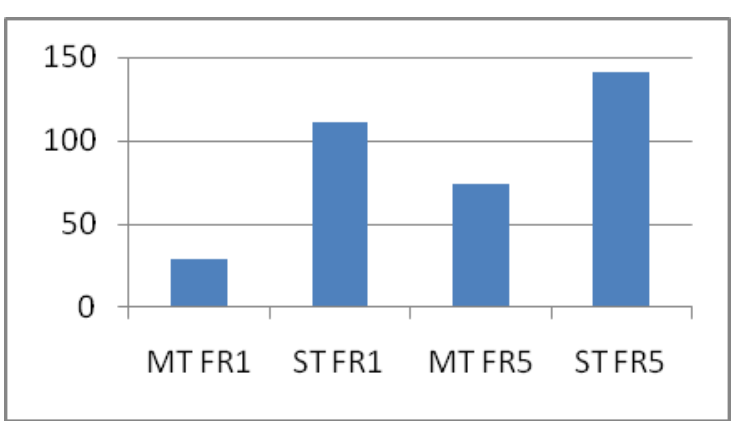

Participant 26

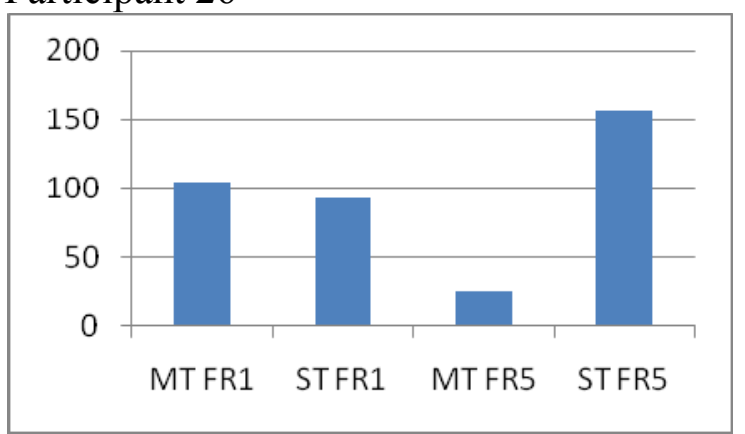

Participant 28

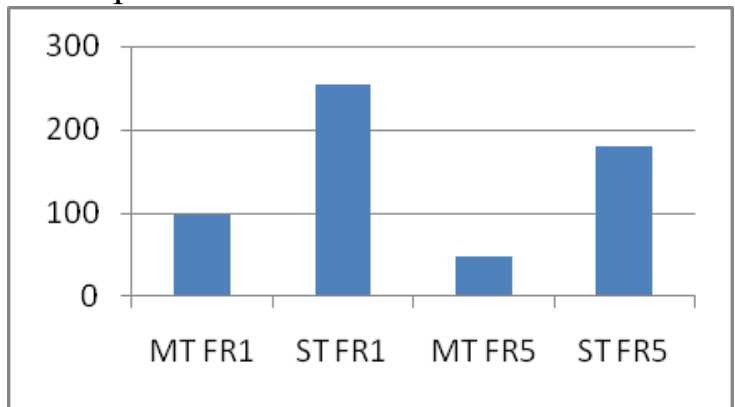

Participant 30 
Trials-to-criterion: When single-task is presented first

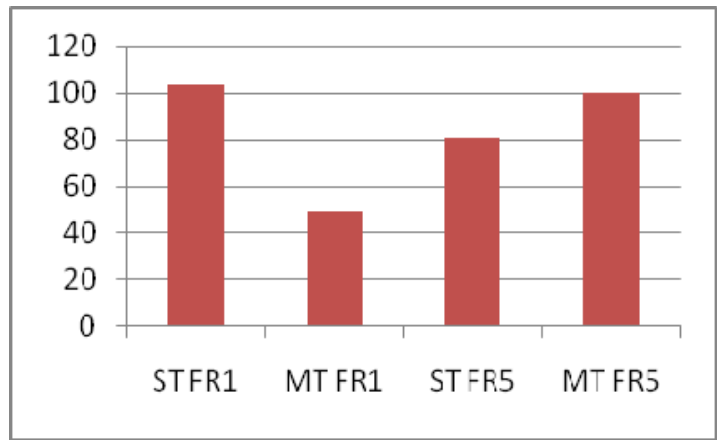

\section{Participant 1}

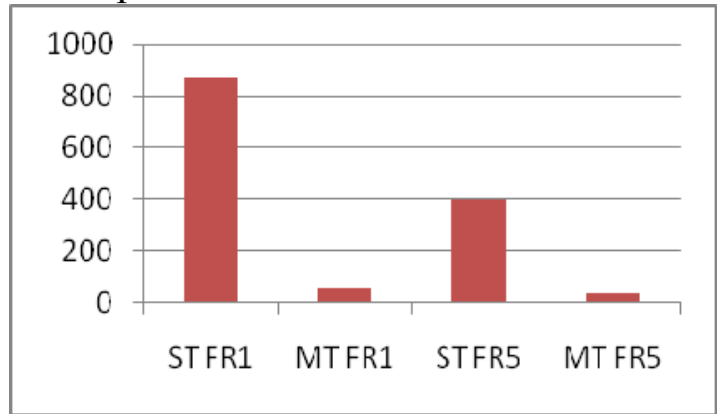

Participant 3

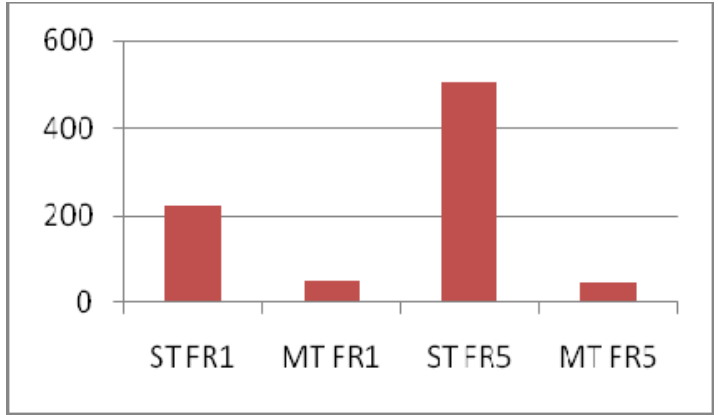

\section{Participant5}

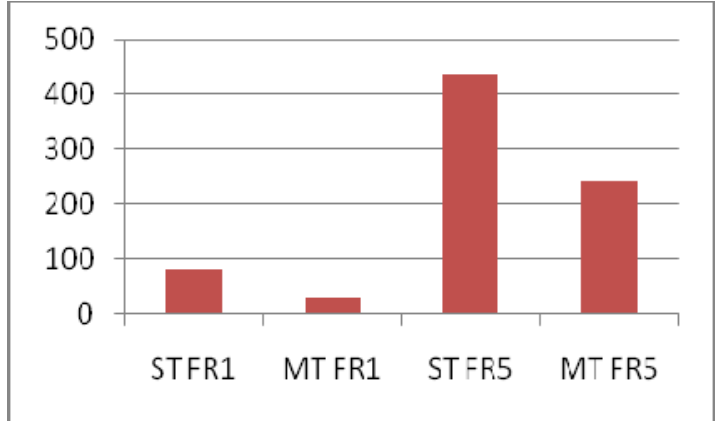

Participant 7

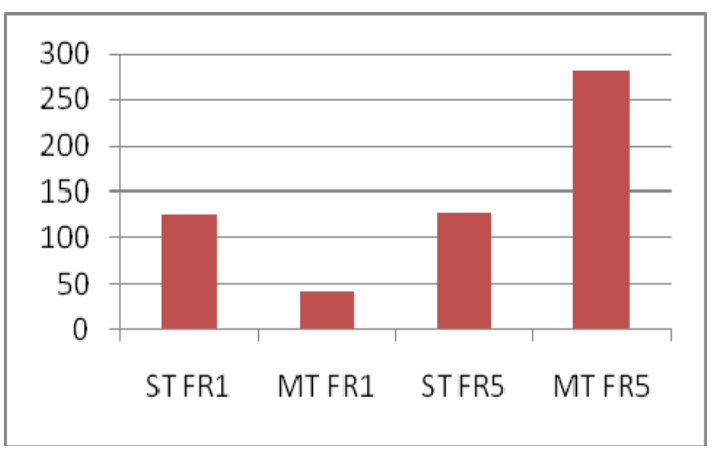

\section{Participant 9}

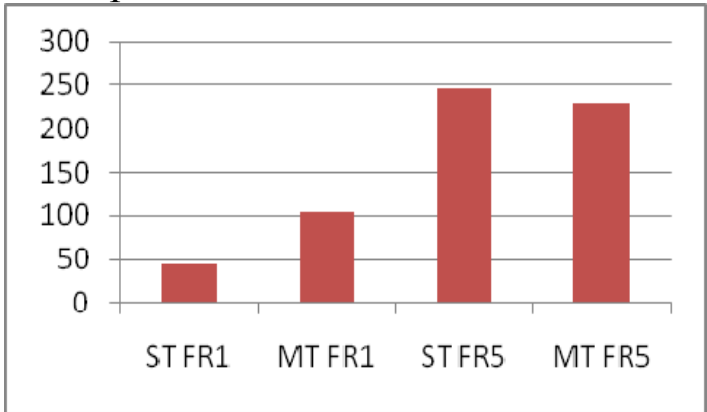

\section{Participant 11}

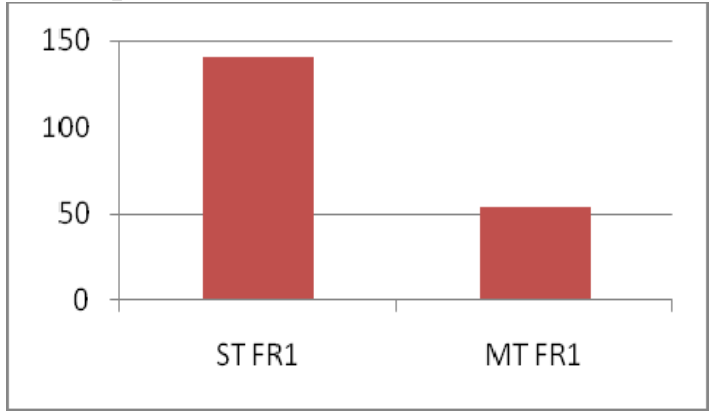

\section{Participant 15}

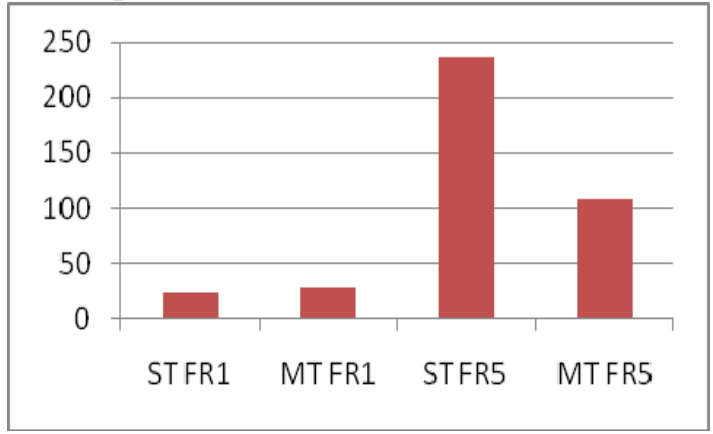

Participant 25 


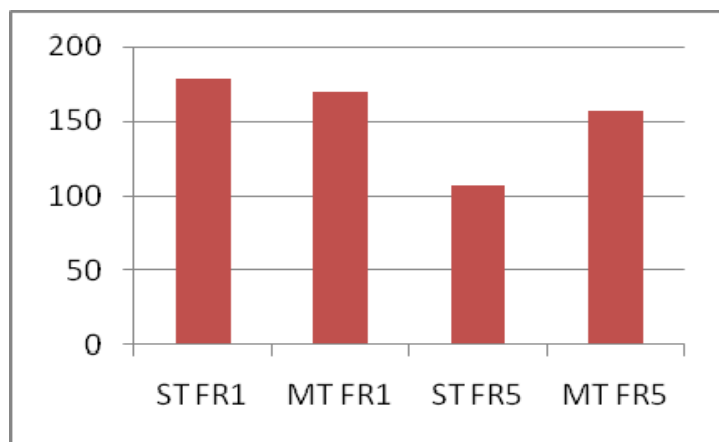

Participant 27

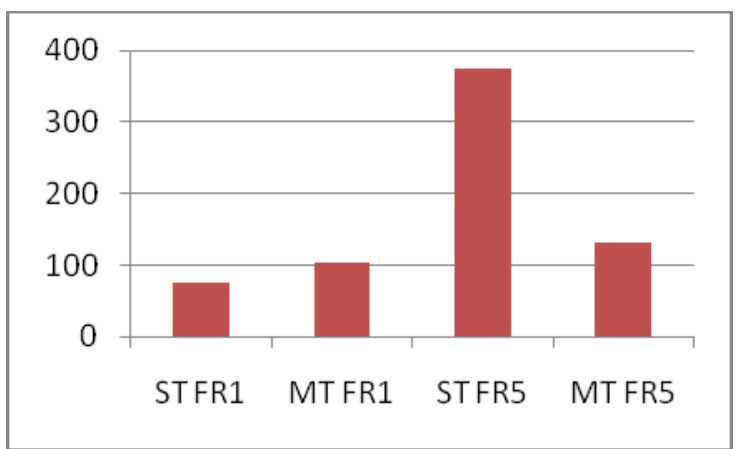

Participant 29 